
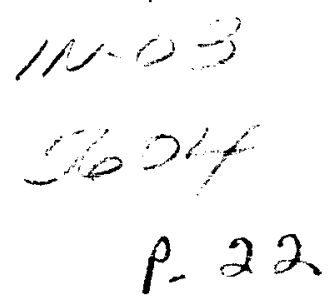

\title{
System Identification Methods for Aircraft Flight Control Development and Validation
}

Mark B. Tischler

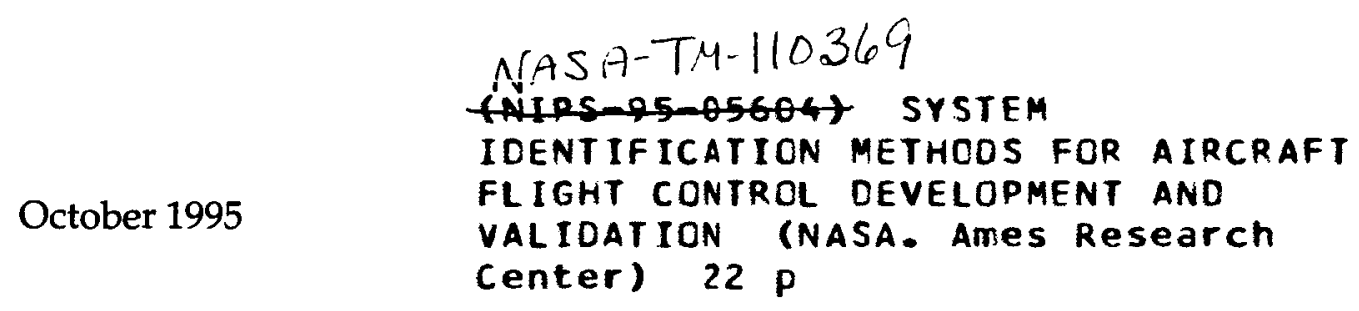

N96-13229

IDENTIFICATION METHOOS FOR AIRCRAFT

VALIDATION (NASA. Ames Research

(enter) $22 \mathrm{p}$

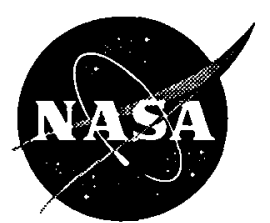

National Aeronautics and Space Administration

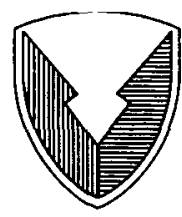

US Army Aviation and Troop Command 


\section{System Identification Methods for Aircraft Flight Control Development and Validation}

Mark B. Tischler, Aeroflightdynamics Directorate, U.S. Army ATCOM, Ames Research Center, Moffett Field, California

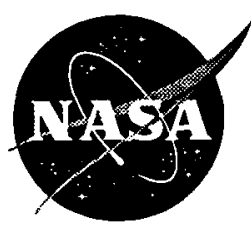

National Aeronautics and Space Administration

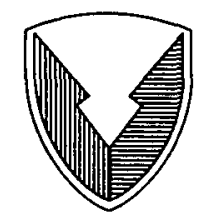

US Army

Aviation and Troop Command

Aeroflightdynamics Directorate Moffett Field, CA 94035-1000 


\title{
System Identification Methods for Aircraft Flight Control Development and Validation
}

\author{
MARK B. TISCHLER \\ Aeroflightdynamics Directorate, U.S. Army ATCOM \\ Ames Research Center
}

\section{Summary}

System-identification methods compose a mathematical model, or series of models, from measurements of inputs and outputs of dynamic systems. The extracted models allow the characterization of the response of the overall aircraft or component subsystem behavior, such as actuators and on-board signal processing algorithms. This paper discusses the use of frequency-domain systemidentification methods for the development and integration of aircraft flight-control systems. The extraction and analysis of models of varying complexity from nonparametric frequency-responses to transfer-functions and high-order state-space representations is illustrated using the Comprehensive Identification from ErEquency Responses (CIFER ${ }^{\circledR}$ ) system-identification facility. Results are presented for test data of numerous flight and simulation programs at the Ames Research Center including rotorcraft, fixed-wing aircraft, advanced short takeoff and vertical landing (ASTOVL), vertical/short takeoff and landing (V/STOL), tiltrotor aircraft, and rotor experiments in the wind tunnel. Excellent system characterization and dynamic response prediction is achieved for this wide class of systems. Examples illustrate the role of systemidentification technology in providing an integrated flow of dynamic response data around the entire life-cycle of aircraft development from initial specifications, through simulation and bench testing, and into flight-test optimization.

\section{Introduction}

System identification is a procedure for accurately characterizing the dynamic response behavior of a complete aircraft, subsystem, or individual component from measured data. This key technology for modern fly-by-wire flightcontrol system development and integration provides a unified flow of information regarding system performance around the entire life cycle from specification and design through development and flight test (fig. 1). A similar "roadmap" for application of system-identification methods to rotorcraft development was previously proposed by
Schrage in a comprehensive report dedicated to this topic (Anon. 1991). An excellent historical summary and overview of system identification is given by Hamel (1995). System identification has been widely utilized in recent aircraft programs including many of those described in the present volume. Common applications for flight-control system development include: definition of system requirements, specification and analysis of handling qualities, evaluation of proposed control-law concepts, validation and improvement of complex simulation models, validation of subsystem components and development facilities, and flight-test optimization of control laws.

Frequency-domain identification approaches are especially well suited to the development and validation of flight-control systems. Feedback stability and noise amplification properties are determined from the brokenloop frequency response, and characterized by metrics such as crossover frequency, and associated gain and phase margins. Command tracking performance is determined from the closed-loop frequency-response, and characterized metrics such as bandwidth and time-delay, and equivalent system eigenvalues. Frequency-domain identification approaches allow the direct and rapid (including real-time) identification of these frequency

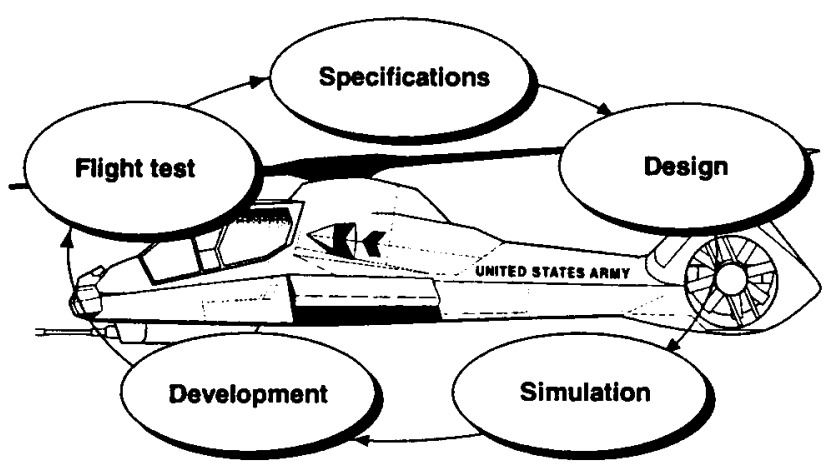

Figure 1. Road map for fly-by-wire flight-control system development and integration. 
responses and metrics, without the need to first identify a parametric (state-space) model structure such as is required in applying time-domain methods. Careful tracking of the broken-loop and end-to-end closed-loop frequency-response behavior from the preliminary design studies through detailed design and simulation and into flight test provides an important "paper trail" for documenting system performance and solving problems that may appear in the later phases of development.

The availability of comprehensive and reliable computational tools has substantially enhanced the acceptability of frequency-domain techniques in the flight-control and flight-test community. Benefits from applying these techniques include the reduction of flight-test time required for control system optimization and handling-qualities evaluation, especially for complex control-law architectures, and improvements in the final system performance. Frequency-domain methods offer a transparent understanding of component and end-to-end response characteristics that can be critical in solving system integration problems.

This paper reviews frequency-domain systemidentification methods for development and integration of aircraft flight-control systems. These methods were developed under a long-term research activity at the Ames Research Center by the Army Aeroflightdynamics Direc- torate (AFDD), the NASA and Sterling Software. Many of the flight applications have been to rotorcraft, which pose an especially difficult challenge to system identification (Tischler 1990). The dynamics of these aircraft are highly coupled, and unstable. Additionally, the rotorcraft dynamics include lightly-damped fuselage and rotor modes. Vibration and low excitation signal content, especially near hover, results in typically low signal-to-noise ratios. Experience in developing and applying systemidentification methods to the rotorcraft problem has produced a set of tools that has proven highly reliable for the broad scope of applications reviewed in this paper. The first section presents a summary of the frequency-domain approach and the Comprehensive Identification from ErEquency Responses (CIFER ${ }^{\left({ }^{\circledR}\right.}$ ) comprehensive analysis facility. The remainder of the paper is organized into five sections following the flight-control development flowchart of figure 1 from specifications and design through flight-test optimization. Each section illustrates important techniques with examples based on fixed and rotary-wing projects at the Ames Research Center.

\section{Overview of AFDD/NASA System- Identification Techniques}

The AFDD/NASA frequency-domain system identification procedure is shown in figure 2 , and in reviewed in

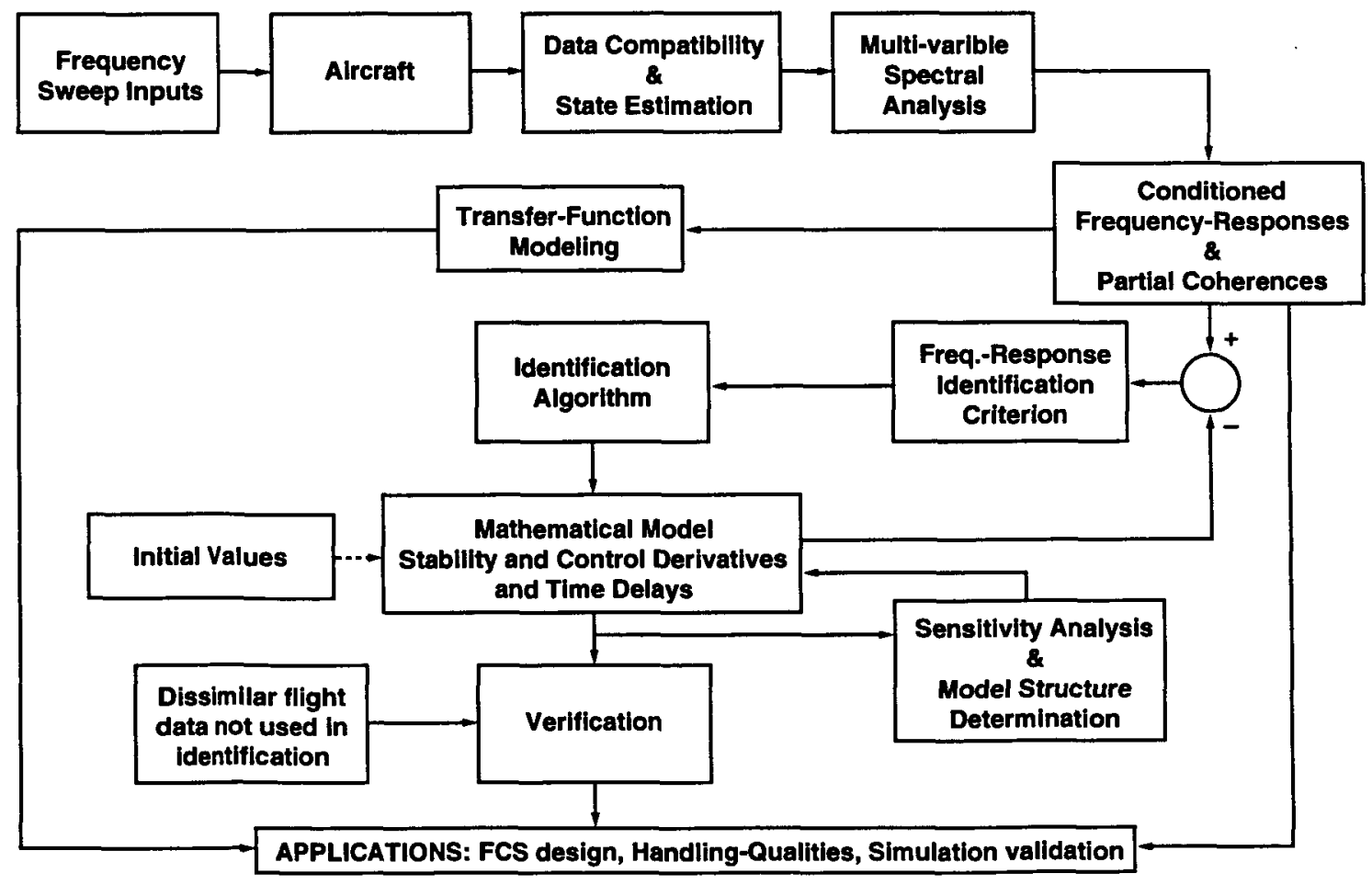

Figure 2. Frequency-domain system identification procedure. 
this section. Details of the procedure are found in Tischler and Cauffman (1992). System-identification methods and requirements for specific application to high-bandwidth rotorcraft flight-control system design are given by Tischler (1990).

Aircraft or subsystem component dynamics are excited by a pilot-generated or computer-generated frequency-sweep input. The dynamic responses are generally measured by dedicated sensors, and the data are either recorded onboard or telemetered to the ground for processing. Kalman filtering techniques (or simple numerical integration) are used to check data compatibility and eliminate spurious instrumentation system biases, scale factors, and drop-outs. Here, unmeasured signals may be estimated from the available measured states.

The foundation of the AFDD/NASA approach is the highquality extraction of a complete multi-input/multi-output (MIMO) frequency-response database. These responses fully characterize the linearized coupled characteristics of the system without a priori assumptions. Advanced multivariable spectral analysis using the Chirp- $Z$ transform and composite optimal window techniques have been developed and exercised over many flight applications. These methods provide significant improvement in identification quality relative to standard fast Fourier transform (FFT) methods. The frequency-response database directly supports important flight-control system applications including: handling-qualities analysis and specification compliance testing, simulation validation, and servo-loop stability analysis.

Transfer-function fitting is a rapid procedure for extracting simple single-input/single-output parametric models of specific frequency-responses pairs. These transferfunction models define the lower-order equivalent systems (LOES) of the fixed wing handling-qualities specifications (MIL-STD-1797) and directly support root-locus techniques for flight-control system design.

Accurate MIMO state-space models are often needed to support multivariable control-law design, simulation model validation and improvement, and validation of aerodynamic theory or wind tunnel results. Here, sophisticated nonlinear search algorithms are used to extract a general state-space model that matches the complete MIMO input/output frequency-response database. A significant advantage of identifying parametric models from frequency responses is the capability to individually define the appropriate frequency range for each response pair based on the associated coherence function-a valuable accuracy and linearity metric. The coherence function is also useful for automatically selecting error weighting in the cost function independent of the model structure. A methodical and integrated model structure determination procedure simplifies the model to a minimum set of reliable parameters that accurately characterizes the MIMO frequency-response database. Finally, the identified state-space model is validated by comparing predicted time responses with the actual flight responses for test inputs not used in the identification procedure.

The frequency-domain system-identification procedure is incorporated in a sophisticated interactive computational facility known as CIFER ${ }^{\circledR}$-Comprehensive Identification from FrEquency Responses. Integrated data-basing and extensive user-oriented utiiities are distinctive feaiures of CIFER ${ }^{\circledR}$ for organizing and analyzing the large amounts of data which are generated for flight-test identification projects. A screen-driven interface is tied to the database for rapid user interaction. Previous program set-ups and analysis results are retrieved by simply referencing case names. Then, changes can be easily made by moving the cursor around on the user screens and modifying the default or previously saved program parameter values. The changes are then updated in the database with a single key stroke. Utilities are available for quick inspection, searching, plotting, or tabulated output of the contents of the database. Extensive analysis modules within CIFER ${ }^{\circledR}$ support: 1) rapid identification of transfer-function models; 2) signal spectral analysis; 3 ) handling qualities and classical servo-loop analysis; and 4) time and frequencydomain comparisons of identification and simulation model predictions with flight data. Aircraft applications of CIFER $^{\circledR}$ have included the full life-cycle of flight-control system development depicted in figure 1 . The Deutsche Forschungsanstalt für Luft- und Raumfahrt (DLR) Institute for Flight Mechanics (Braunschweig, Germany) has also developed and widely applied excellent methods for frequency-domain system identification. Applications to flight-mechanics and flight-control studies at the DLR include rotorcraft, transport aircraft, and highperformance aircraft (Kaletka and von Grunhagen 1989, Kaletka and Fu 1993).

\section{Design Specifications and Specification Acceptance Testing}

Formulating design specifications is the starting point for flight-control system development, while validating the achievement of these design goals is the concluding step in the process (fig. 1). Dynamic models of expected system behavior are determined in the design process using system identification and are tracked and updated throughout the aircraft development and flight testing. This documentation provides an important "paper trail" that minimizes flight-control development time and reduces the need for costly flight-test tuning. This section presents system-identification methods for defining and 
verifying design specifications. Flight test examples illustrate the analysis of handling qualities and servo-loop stability characteristics.

Early handling-qualities specifications for fixed-wing aircraft (MIL-F-8785A, Anon. 1954), and for rotary-wing aircraft (MIL-H-8501 A, Anon. 1961) were based on simple dynamic modeling concepts and time-domain metrics. These specifications were suitable to aircraft in which stability augmentation systems (SAS) did not significantly alter the character of the (classical) bare-airframe flightmechanics responses. Compliance testing techniques depended on standard step and doublet inputs long used in the flight-test community, with little requirement for sophisticated post-flight-data processing.

Modern fly-by-wire aircraft employ high-bandwidth digital flight-control systems to achieve greatly increased agility and disturbance rejection across a significantly widened operational flight envelope as compared with the older generation of aircraft. The flight control includes complex feedback and feedforward shaping and advanced control moment devices that profoundly alter the bareairframe characteristics and invalidate the classical stability and control modeling concepts and testing methods. For example, modern combat aircraft achieve independent pitch pointing and flightpath control with direct lift devices and vectored thrust, rather than the coupled attitude-path response to elevator for conventional aircraft. This capability greatly enhances weapon pointing and air-to-air combat maneuvering. Another common feature of advanced aircraft is side-stick controllers which reduce weight, space, and cockpit complexity compared to standard center-sticks. Classical static stick-stability testing is an invalid method for determining speed stability since the side-sticks possess automatic trimming at neutral stick position and feedback loops provide the required stability independent of the trim gradient.

A new concern that arises for modern fly-by-wire aircraft is the potential for the accumulation of effective time delays due to digital flight-control computations, flightcontrol system filters, and fly-by-wire actuators. Actuator rate-limiting can also contribute large equivalent time delays in modern aircraft (Buchholz et al. 1995). Excessive delays have been repeatedly cited as a key cause for handling-quality problems and stability-loop margin degradation in modern aircraft, yet equivalent time delay can not be reliably measured using the standard testing techniques. Clearly the dynamics modeling concepts, specifications, and testing techniques must be appropriate to the unique characteristics of modern highly-augmented aircraft.

System identification provides an accurate, rapid, and reliable approach for defining design specifications and for validating aircraft flight performance for highlyaugmented flight-control systems. The modern U.S. fixedwing specification (MIL-STD-1797; Anon. 1987) and rotorcraft specification (ADS-33C; Anon. 1989) are based on extensive frequency-domain system-identification analyses of flight-test and simulation responses. Numerous examples from these and comparable European handling-qualities specifications are presented in this volume and in the references of this paper. Two common handling-quality specifications are the bandwidth/phasedelay criteria and the LOES criteria. The former is checked directly from frequency-response identification, and the latter is checked from a transfer function fit of the frequency-response result. An illustration of flight-test and handling-qualities analyses based on these specifications is now presented.

The Advanced Digital Optical Control System (ADOCS) demonstrator (fig. 3), developed by Boeing's Helicopters Division under contract to the U.S. Army, was a UH-60A helicopter highly modified with redundant processors, instrumentation, and side-stick controllers (Glusman et al 1987). The overall program objective of the ADOCS was to provide the technology base for the engineering development of an advanced battlefield-compatible flight-control system that: 1) enhanced aircraft mission capability; 2) improved handling qualities; and 3) decreased pilot workload. System identification flight tests and analyses using CIFER ${ }^{\circledR}$ were conducted to document the response characteristics and to compare handling-qualities characteristics with the (proposed at that time) ADS-33 design specifications (Hoh et al. 1988). Aircraft excitation was achieved via piloted frequency sweeps using the side-stick controller as shown in figure 4. Real-time telemetry of pilot inputs and aircraft responses ensured that preestablished aircraft flight limits were not exceeded.

The ADOCS frequency response for pitch response due to longitudinal input is shown in figure 5 , along with the

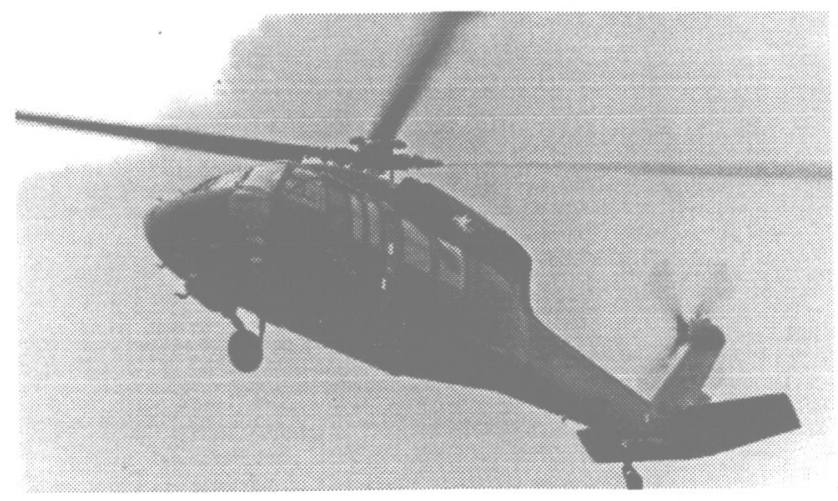

Figure 3. Advanced digital optical control system (ADOCS) demonstrator. 

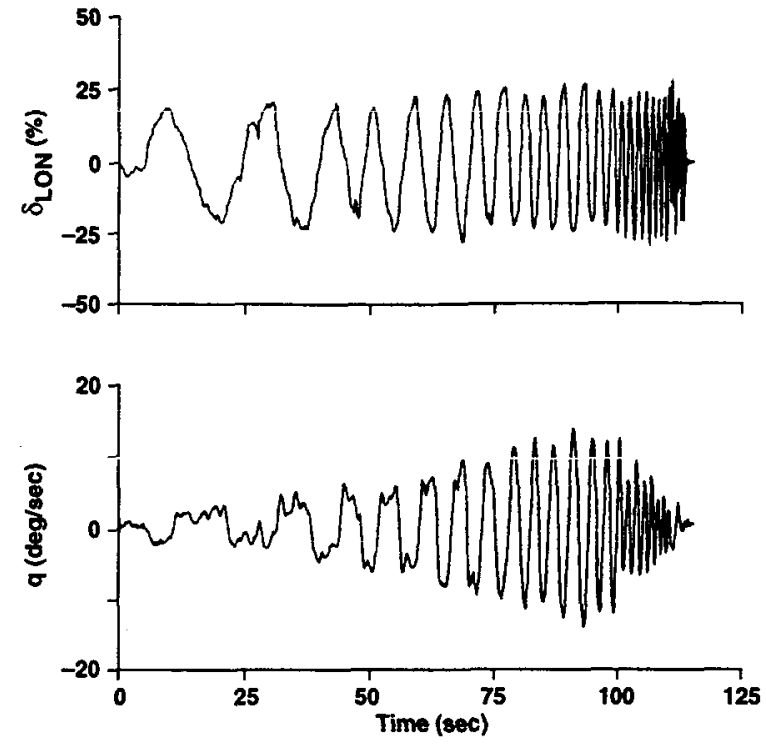

Figure 4. Longitudinal side-stick frequency-sweep in hover; (a) pitch input, (b) pitch rate.
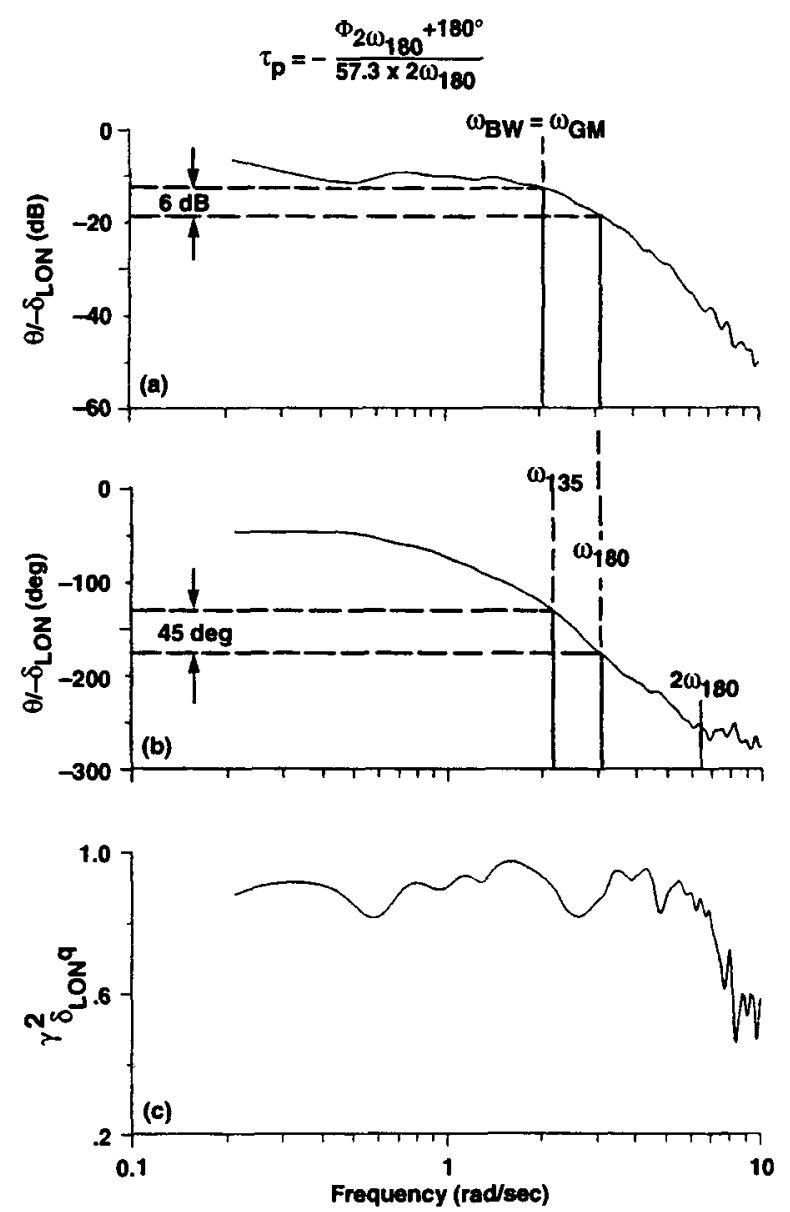

Figure 5. Identification of ADOCS pitch-rate response in hover. determination of bandwidth and phase delay as required by the ADS-33 specification. The value of the coherence function (fig. 5 ) is consistentily above 0.8 for the frequency range of $0.2-8 \mathrm{rad} / \mathrm{sec}$ indicating excellent identification. At higher frequencies, the coherence drops, which reflects the intentionally reduced piloted inputs. The pitch bandwidth and phase delay values obtained from the hover identification results are shown on the ADS-33 specification boundary in figure 6. Level I (satisfactory) handling qualities for moderate pilot-gain tasks such as the heliconter "hoh-un" are predicted, which is consistent with the Cooper-Harper pilot rating displayed next to the data symbol. A good correlation of pilot rating and the predicted handling qualities result was also indicated in pitch for the $80 \mathrm{kt}$ flight condition.

Transfer-function (LOES) models of the key on-axes responses were generated from single-input/single-output fits of the identified ADOCS frequency responses. The LOES pitch response in hover is:

$$
\frac{\theta}{\delta_{\mathrm{LON}}}=\frac{-0.876(\mathrm{~s}+0.229) \mathrm{e}^{-0.238 \mathrm{~s}}}{\mathrm{~s}[0.539,1.82]}
$$

The response is dominated by a well-damped secondorder mode with a frequency of $1.8 \mathrm{rad} / \mathrm{sec}$. The LOES handling-qualities specification boundaries of figure 7 have been established based on system-identification analyses of an extensive flight-test and simulation data base (Hoh and Ashkenas 1979). The ADOCS characteristics are seen to lie well within the Level I region. A second important characteristic of the LOES pitch response is

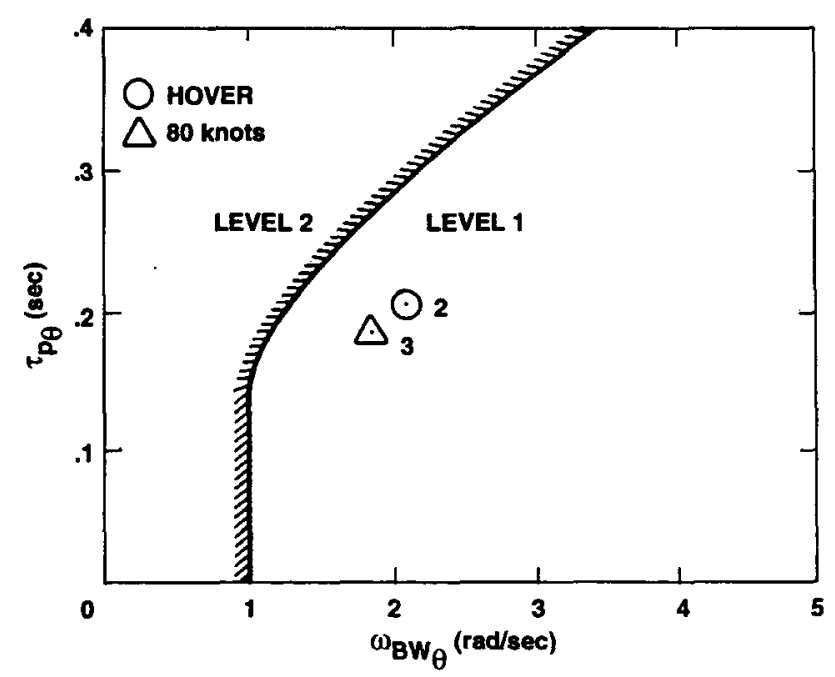

Figure 6. Handling-qualities correlation of ADOCS small amplitude pitch response in hover and $80 \mathrm{kt}$; average pilot ratings are shown next to the data. 

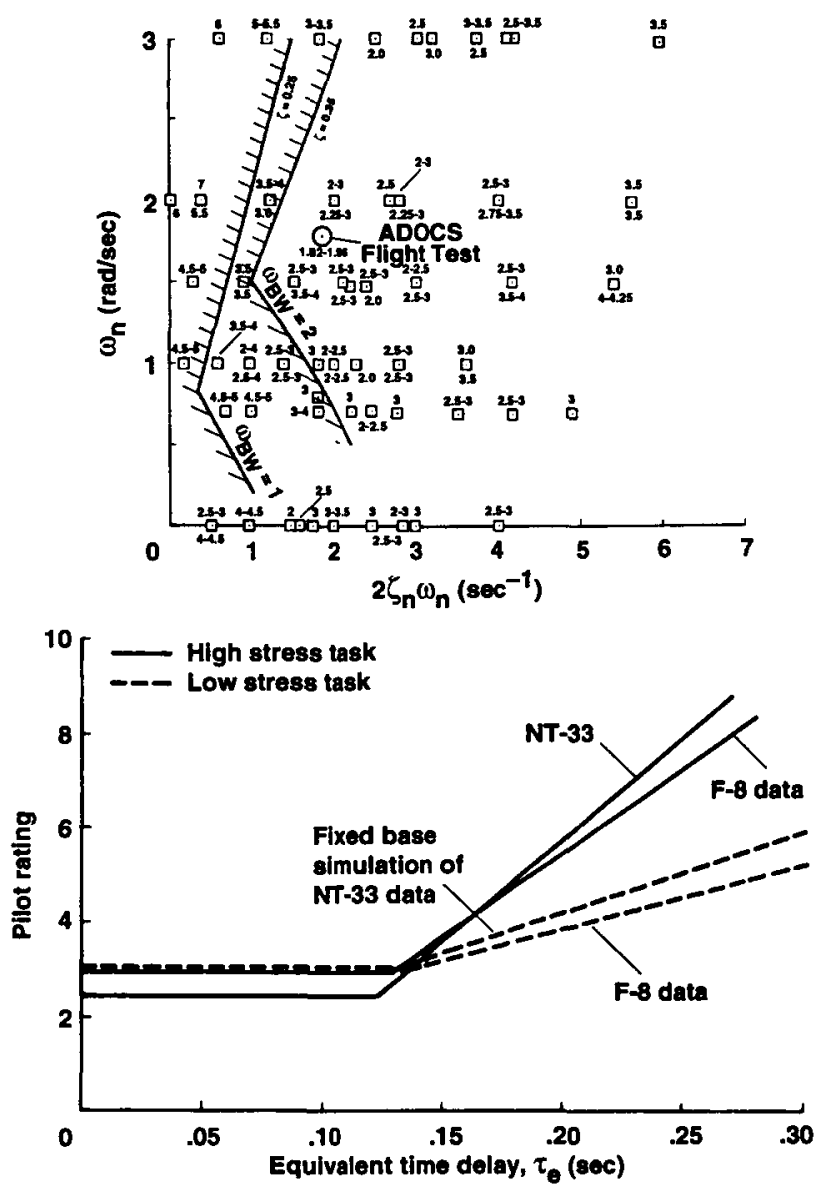

Figure 7. Correlation of ADOCS LOES pitch response with handling-qualities data.

the relatively large equivalent time delay, $\tau=238 \mathrm{msec}$. Handling-qualities experience indicates that the equivalent time delay should not greatly exceed $\tau=120 \mathrm{msec}$, thereby suggesting ADOCS handling-qualities degradation for "high-gain" tasks. Comparable levels of equivalent time delay in the roll axis were considered to be a key contributor to pilot-induced oscillations (PIO) for "highgain" piloting tasks such as slope landing (Tischler et al. 1991). Additional examples of handling-qualities analyses using lower-order equivalent-system modeling are presented in this volume.

The stability characteristics of aircraft rigid-body and structural dynamics may be greatly affected by the feedback loops of the flight-control system. Feedback may degrade the flutter margin stability at the same time it improves the rigid-body stability and handling qualities. Military specification 9490D (Anon. 1975) defines minimum levels of control system gain and phase margin as determined from a broken servo-loop frequency-response analysis. The specifications are given as a function of fre- quency range, with larger gain margins required for the structural elastic modes (table 1). Figure 8 shows the broken servo-loop frequency response of a large single-rotor helicopter as obtained by computer-generated frequencysweep flight-test procedures. The rigid-body response crossover frequency is $2.0 \mathrm{rad} / \mathrm{sec}$ with an associated phase margin of $28 \mathrm{deg}$. This margin is slightly below the recommended specification value. The gain margin is checked at each crossing of the $180 \mathrm{deg}( \pm n 360)$ phase line as shown in the figure. The critical margin is the minimum value ( $\left(\mathrm{GM}_{5}\right)$, which is $15 \mathrm{~dB}$ at a frequency of $23.5 \mathrm{rad} / \mathrm{sec}$. This frequency corresponds to the first vertical bending mode for the tail boom of this aircraft. Reference to table 1 indicates this gain margin to be well within accepted design specifications. The coherence function of figure 8 shows excellent identification accuracy for this flight test across the broad frequency range of interest (1-30 rad/sec). Sharp drops ("holes") or peaks in the coherence function reflect structural anti-nodes and nodes respectively. Examples of fixed-wing programs

Table 1. MLL-F-9490D gain and phase margin requirements (dB, deg) from Caldwell (1994)

\begin{tabular}{|c|c|c|c|c|}
\hline $\begin{array}{l}\text { Alrepeed } \\
\text { Mode Freq. Hz }\end{array}$ & $\begin{array}{l}\text { Below } \\
V_{\text {o min }}\end{array}$ & $\begin{array}{l}V_{0 \text { min }} \\
\text { to } \\
V_{0 \text { max }}\end{array}$ & $\begin{array}{l}\text { At } \\
\text { Limit Speed } \\
V_{L}\end{array}$ & $\begin{array}{l}\text { At } \\
1.15 \cdot V_{L}\end{array}$ \\
\hline$t_{M}<0.06$ & \multirow{3}{*}{$\begin{array}{l}\mathrm{GM}=6 \mathrm{~dB} \\
\text { No Phase } \\
\text { Reqt. } \\
\text { below } \\
\mathrm{V}_{\text {o min }}\end{array}$} & $\begin{array}{l}\mathrm{GM}= \pm 4.5 \\
\mathrm{PM}= \pm 30\end{array}$ & $\begin{array}{l}\mathrm{GM}= \pm 3.0 \\
\mathrm{PM}= \pm 20\end{array}$ & \multirow{3}{*}{$\begin{array}{l}\text { GM }=0.0 \\
\text { PM }=0.0 \\
\text { Stable } \\
\text { at } \\
\text { Nominal } \\
\text { Phase } \\
\text { and } \\
\text { Gain }\end{array}$} \\
\hline $0.06 \leq f_{M}<$ tst ASE & & $\begin{array}{l}G M= \pm 6.0 \\
P M= \pm 45\end{array}$ & $\begin{array}{l}\mathrm{GM}= \pm 4.5 \\
\mathrm{PM}= \pm 30\end{array}$ & \\
\hline 1 st ASE $<f_{M}$ & & $\begin{array}{l}G M= \pm 8.0 \\
P M= \pm 60\end{array}$ & $\begin{array}{l}G M= \pm 6.0 \\
P M= \pm 45\end{array}$ & \\
\hline
\end{tabular}

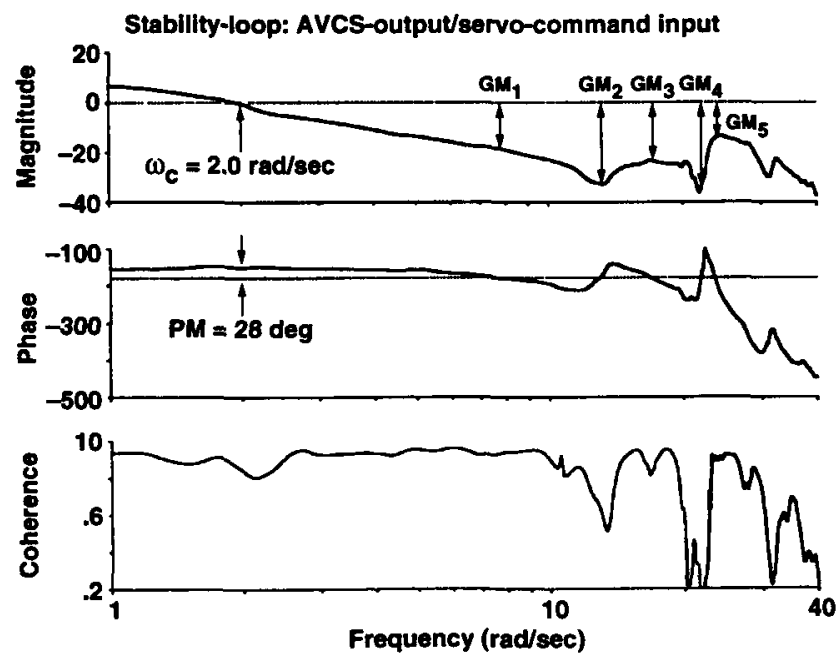

Figure 8. Rotorcraft servo-elastic stability margin testing. 
using frequency-domain system identification for elastic mode stability-margin evaluation include the X-29 (Clarke et al. 1994) and EAP (Caldwell 1994) aircraft.

\section{Design}

The design process establishes control system loop architecture and associated control-law parameters that achieve desired handling-qualities and servo-loop stability specifications. During the conceptual design phase, systemidentification procedures are applied tó simple liñeardesign models to establish a baseline description of the proposed control system approaches and an initial check of specification compliance. At the detailed design stage, system-identification methods can extract highly-accurate linear-control system design models from complex simulation models or wind-tunnel data. These applications of system identification in the design process are illustrated in this section.

Conceptual control-system design studies are commonly based on simple stability and control derivative descriptions and transfer function of the airframe dynamics as obtained from first-principles aerodynamic theory. Control-law architectures are conceived and the initial system is modeled in a computer-aided design (CAD) environment such as MATLAB ${ }^{\circledR}$ (1992). System identification provides LOES models which are very useful in characterizing the end-to-end system dynamics and delays, and for an initial check against the design specifications. Flight-control system design parameters are then adjusted until the identified LOES characteristics satisfy the design requirements. In the F-15 S/MTD demonstrator project, a numerical optimization design tool was developed to automatically adjust control-law parameters to meet LOES specifications (Moorhouse and Citurs 1994).

Detailed flight-control design efforts are based on very complex high-order and nonlinear-simulation models. Force and moment descriptions are developed for each of the aircraft elements such as the wings, propulsion system, and flight-control systems based on wind tunnel look-up tables, component bench-test data, and analytical theory. The simulation of multiple rigid-body systems, or flexible bodies involves sets of dynamic equations of motion linked by constraint conditions. In many simulations these sets of equations are numerically integrated in serial form to reduce the complexity of deriving a fullycoupled multibody simulation. The distributed or serial nature of these complex simulations thus may preclude the extraction of an integrated high-order linear model of the fully-coupled system as is needed for accurate controldesign studies.
Even when the simulation architecture allows for the direct extraction of higher-order linear models using classical numerical perturbation methods, the assumption of independent perturbations results in incorrect phasing of the state variables within the multidimensional look-up tables. For example, the look-up table for aerodynamic pitching moment may depend both on angle of attack and pitch rate, so $C_{m_{q}}=f(\alpha)$. Thus, the correct determination of phugoid dynamics depends on maintaining representative phasing of $q$ and $\alpha$ within the linearization process. Selection of perturbation size can also strongly influence the linearization results. These effects can significantly degrade the predictive accuracy of the extracted linear model. Much more accurate linear models are obtained by simulating piloted frequency-sweep inputs and extracting state-space models using system identification just as if from flight-test data.

Engelland extracted accurate stability and control derivative models of a conceptual A/STOVL aircraft from a complex nonlinear off-line simulation (Engelland et al. 1990) to support control-system design studies. The excitation input consisted of computer-generated frequency sweeps and white noise. In a procedure described by Ballin and DalangSecretan (1991), artificial feedback control loops were included to keep the aircraft flight condition near the reference trim point during the inputs. Starting from the perturbation derivative results CIFER ${ }^{\circledR}$ was used to identify a more accurate 6 DOF bareairframe model. The perturbation and CIFER ${ }^{\circledR}$ derivatives are compared in table 2 . Longitudinal-frequency responses of the two linear models are compared with the complete simulation responses in figure 9 for a flight condition of 120 knots. The linear model obtained using system identification is seen to be much more accurate than the numerical perturbation model for the high-frequency (3.0-20 rad/sec) pitch-rate response $q / \delta_{\theta}$, and for the low-frequency $(0.1-1.0 \mathrm{rad} / \mathrm{sec})$ longitudinal-acceleration response $a_{x} / \delta_{\theta}$. The models are essentially identical in the mid-frequency range. A time domain comparison of the two-linear models with the nonlinear-simulation response is shown in figure 10 for a small ( $1 \mathrm{deg}$ ) pitch-doublet input. The system-identification model is seen to track the nonlinear behavior much more closely than the numerical perturbation model. The improvements are most noticeable for the long-term response (low-frequency) behavior, which is consistent with the frequencyresponse comparison of figure 9 . 
Table 2. Comparison of ASTOVL perturbation derivatives and CIFER ${ }^{\circ}$ results

\begin{tabular}{|l|r|r|r|r|}
\hline Derivative & Perturb. Value & CIFER Value & C.R. (\%) & Insens. (\%) \\
\hline$X_{u}$ & -0.03471 & -0.03602 & -5.662 & 2.289 \\
$X_{W}$ & 0.03958 & 0.02852 & 6.910 & 2.840 \\
$X_{\dot{w}}$ & $6.764 \mathrm{E}-04$ & $6.764 \mathrm{E}-04 \dagger$ & - & - \\
$X_{q}$ & 0.2451 & $0.2451 \dagger$ & - & - \\
$X_{P C D}$ & $-7.690 \mathrm{E}-03$ & $-8.303 \mathrm{E}-03$ & -7.504 & 3.584 \\
$X_{P L A}$ & 0.02270 & 0.02229 & 3.731 & 1.835 \\
$X_{\Theta}$ & -0.5150 & -0.5586 & -2.353 & 1.005 \\
$Z_{u}$ & -0.04596 & -0.03312 & -13.62 & 4.579 \\
$Z_{W}$ & -0.3704 & -0.2817 & -4.386 & 1.377 \\
$Z_{\dot{W}}$ & -0.01023 & $-0.01023 \dagger$ & - & - \\
$Z_{q}$ & -3.754 & $-3.754 \dagger$ & - & - \\
$Z_{P C D}$ & 0.1389 & 0.1551 & 5.571 & 2.698 \\
$Z_{P L A}$ & -0.3800 & -0.3305 & -2.254 & 1.016 \\
$Z_{\Theta N}$ & -0.01724 & -0.03055 & -4.646 & 2.242 \\
$M_{u}$ & $1.661 E-04$ & $-1.059 E-03$ & -6.016 & 1.745 \\
$M_{W}$ & $1.222 E-03$ & $3.715 E-03$ & 5.263 & 1.283 \\
$M_{\dot{W}}$ & $-1.286 \mathrm{E}-03$ & $-1.286 \mathrm{E}-03 \dagger$ & - & - \\
$M_{q}$ & -0.4971 & -0.6852 & -5.561 & 1.873 \\
$M_{P C D}$ & 0.02494 & 0.02818 & 2.517 & 0.9822 \\
$M_{P L A}$ & $4.993 \mathrm{E}-04$ & $4.993 \mathrm{E}-04 \dagger$ & - & - \\
$M_{\Theta N}$ & $2.502 E-04$ & $4.953 E-04$ & 10.16 & 4.257 \\
\hline
\end{tabular}

† Perturbation value used.

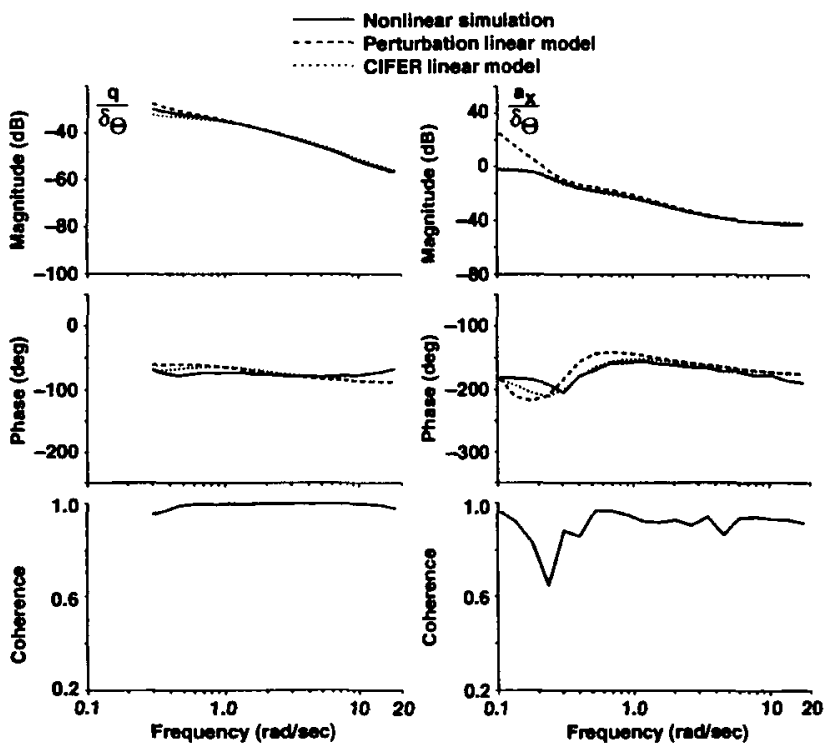

Figure 9. Frequency-response comparison of perturbation and identification models with nonlinear ASTOVL simulation.

These results show that system identification provides an A/STOVL linear model that will be much more accurate than models extracted using numerical perturbation methods. The improvement obtained by "flying" the frequency-sweep input is especially apparent at low

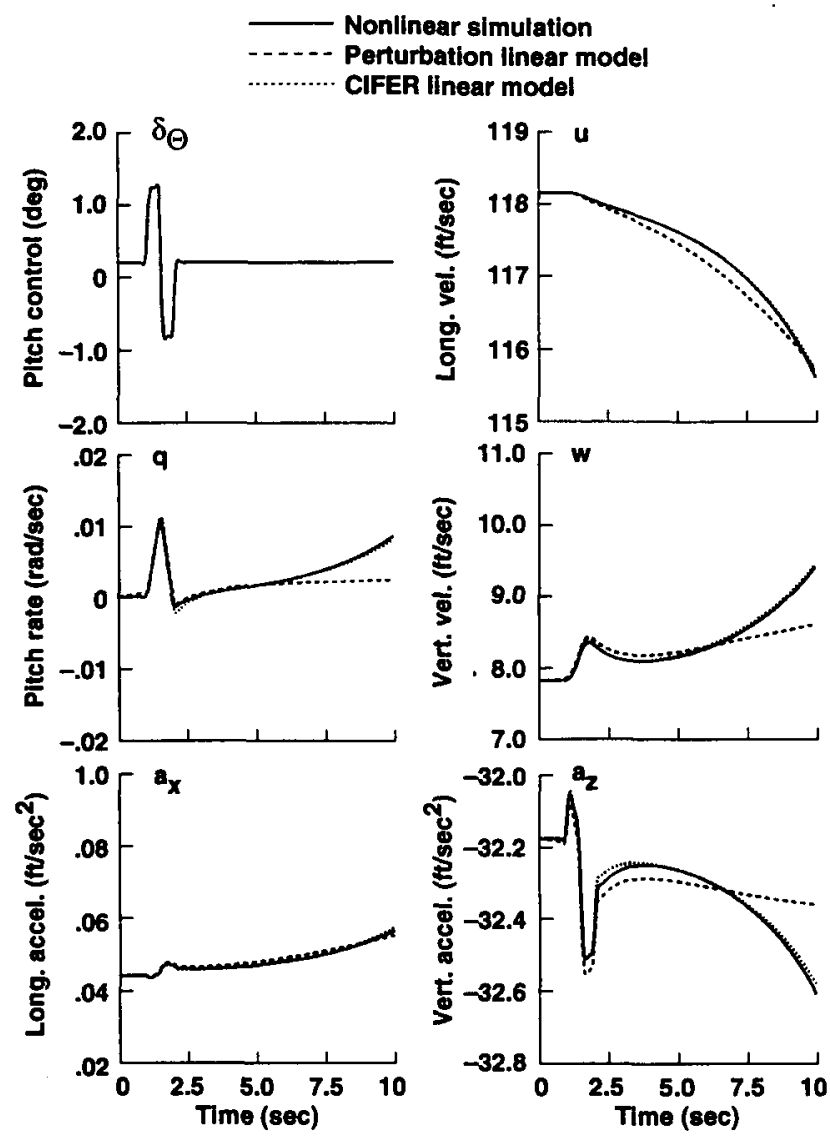

Figure 10. Time-domain comparison of perturbation and identification models with nonlinear simulation of ASTOVL aircraft.

frequencies where the dynamic responses are larger, and correct phasing of the representative motion variables for entry into the multidimensional look-up tables is important. A cursory time-domain comparison of the numerical perturbation results with the nonlinear-simulation response would suggest the presence of strong nonlinearities in the A/STOVL aircraft dynamics. However, the very close agreement of the system-identification model with the nonlinear simulation shows that the method of linear model extraction is much more important in this case than the nonlinear characteristics of the simulation.

Success in achieving maximum control-system performance and robustness in flight depends heavily on the predictive accuracy of the linear-design models. The system identification approach provides highly-accurate design models for design at specific flight conditions, but it is clearly more time intensive than the simple numerical perturbation method. This is not a practical approach for checking control system behavior at the tens or hundreds of off-nominal conditions. 


\section{Simulation}

The detailed implementation of the control-system design is evaluated in comprehensive real-time piloted simulation trials. System-identification techniques are exercised to validate the real-time math model implementation of nonlinear digital control laws. Also, these techniques are used to document simulator motion and visual systems. Once flight-test data are available, system identification provides an important tool for validating and updating the simulation math models. This section illustrates systemidentification techniques for validating simulation math models and simulator validation using XV-15 tilt-rotor (airplane mode) and UH-60A helicopter results. A companion frequency-domain format is proposed for specifying simulation model fidelity for the on-axis responses. Finally, an analysis based on an A/STOVL piloted simulation study illustrates the use of system identification for determining actuator authority requirements.

Direct frequency-response comparison of the end-to-end performance of the complex simulation model with the conceptual design models and specifications constitutes an important "dynamic check" which often exposes unexpected processing delays such as in the numerical integration procedures, or errors in the digital (Z-plane) implementation of control laws. This technique is also useful in exposing degradation in control system performance due to high-order structural or other hardware dynamics modeled in the advanced design simulation model that may not have been taken into account in the conceptual studies.

Simulator visual and motion systems should track the math-model response as accurately as possible to ensure that the pilot's cueing environment is correct and that the handling-qualities evaluation obtained in the simulator reflect what may be expected in flight. Nonlinear compensation algorithms have been developed by McFarland (1988) that offset visual system delays, thereby minimizing the mismatch between the simulator visual system response and the math model. In work reported by Atencio (1993) and illustrated in figure 11, there is nearly perfect agreement of the DIG-1 visual system image (with McFarland compensation) and the UH-60A helicopter simulation math model. Math-model commands to the simulator motion drive are attenuated using wash-out logic. The wash-out parameters are selected to preserve the dynamic behavior in the frequency range of most concern to the pilot (e.g., 1-10 rad/sec for pitch and roll tasks), while accommodating the restricted motion environment of the simulator. Figure 12 from Atencio (1993) compares the (washed-out) cab roll-motion to stick input with the math-model response for the UH-60A simulation in the Ames Vertical Motion Simulator (VMS). In the
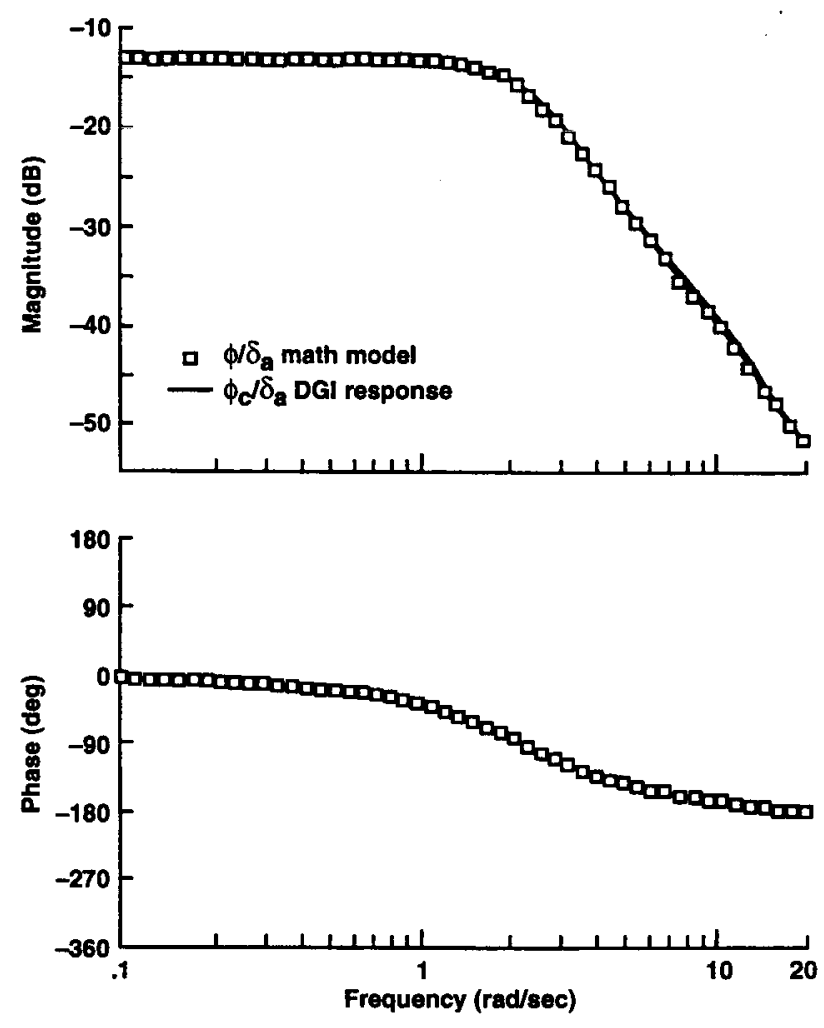

Figure 11. Validation of DIG-1 visual-system response.

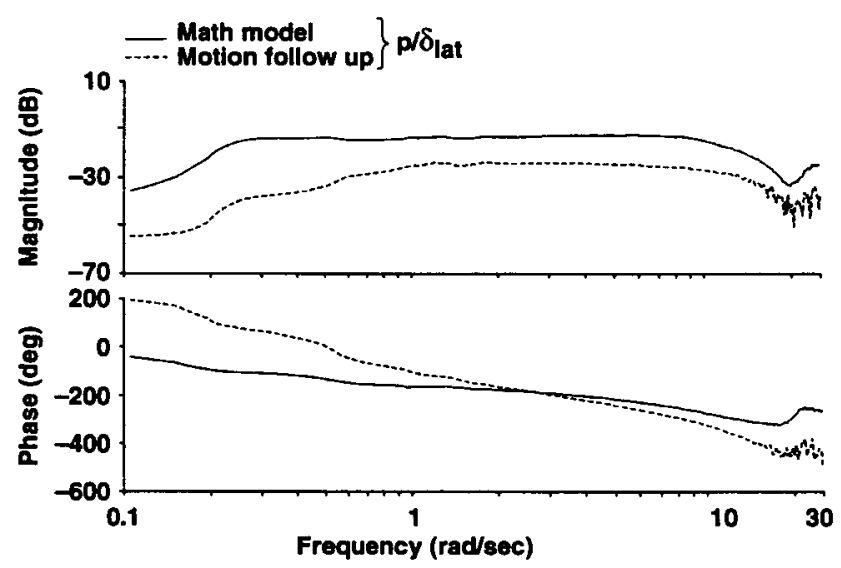

Figure 12. Documentation of VMS motion follow-up for $U H-60 A$ roll response in hover.

$1-10 \mathrm{rad} / \mathrm{sec}$ frequency range, the simulator motion drive response follows the math model, although the motion is less than one-to-one as seen by the vertical shift in the magnitude curves. The motion drive wash-out logic is designed to minimize phase distortions in this frequency range as can be seen in the figure. At low frequencies the large motion is washed-out, and considerable errors are encountered in the magnitude and phase response as 
expected. At high frequency, the motion drive is unable to follow rapid commands to the aircraft model, resulting in larger phase lags of the motion follow-up as seen in the figure.

Once flight-test data are available, system-identification tools are exercised to validate and update the simulation math models. The direct comparison of frequencyresponse behavior provides a clear picture of model fidelity as a function of frequency. This is critical for validating piloted simulations since the requirements on pilot cueing accuracy are also frequency dependent. The separate display of the magnitude and phase responses allows the sources of simulation discrepancies to be more easily determined. For example, an excessive time delay $(\tau)$ in the simulation math model or hardware causes a linear phase shift with frequency $(\phi=-\tau \omega)$. Scaling errors in the simulation model appear as a clear vertical shift (in $\mathrm{dB}$ ) in the magnitude curve. These effects are all combined in the time-domain and therefore are not easily discernible in the traditional time-response comparison methods for validation. Further, the procedure of overlaying time histories is often not very accurate since the flight responses rarely begin in a trim quiescent condition.

Tischler (1987) conducted an extensive flight-test program and simulation math-model validation study on the $\mathrm{XV}$-15 tilt-rotor aircraft shown in figure 13. This tilt-rotor math model is based on comprehensive look-up tables of full-scale wind-tunnel test data, and detailed theoretical models of the rotor-system behavior and rotor-on-airframe aerodynamic interference effects. Figure 14 compares the flight and simulation roll responses for a flight condition of $170 \mathrm{kts}$. Excellent dynamic response fidelity is seen in the close match of the simulation prediction and the measured flight response. Figure 15 replots these results in terms of magnitude and phase errors as a function of frequency. Here $0 \mathrm{~dB}$ magnitude and $0 \mathrm{deg}$ phase indicate perfect tracking of the flight and simulation results. Also shown in the figure are math model mismatch boundaries proposed herein for the highest fidelity training simulations (FAA Level D). These boundaries correspond to the LOES mismatch criteria from the fixed-wing handlingqualities criteria (Hoh et al. 1982). The XV-15 simulation math model complies with the proposed Level D (highfidelity) criteria. This result is consistent with the very favorable pilot comparison of simulator and flight behavior (Churchill and Dugan 1982). The same approach has also been proposed and applied by the DLR for evaluating the fidelity of in-flight simulation (Buchholz et al. 1995).

Direct comparisons of stability and control derivatives identified from flight tests with values identified from simulation math models can be used to derive correction

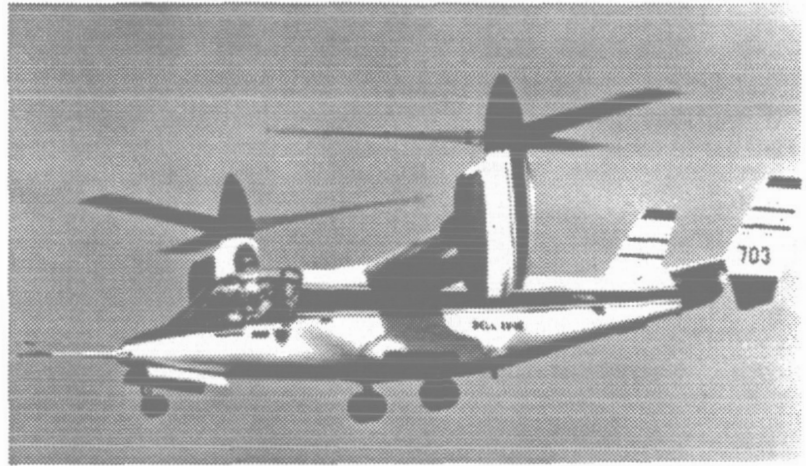

(a)

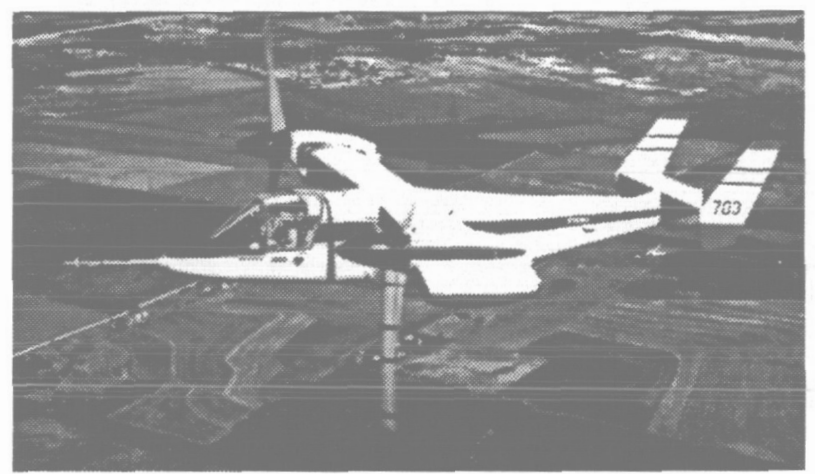

(b)

Figure 13. XV-15 tilt-rotor aircraft; (a) hover configuration, (b) cruise configuration.

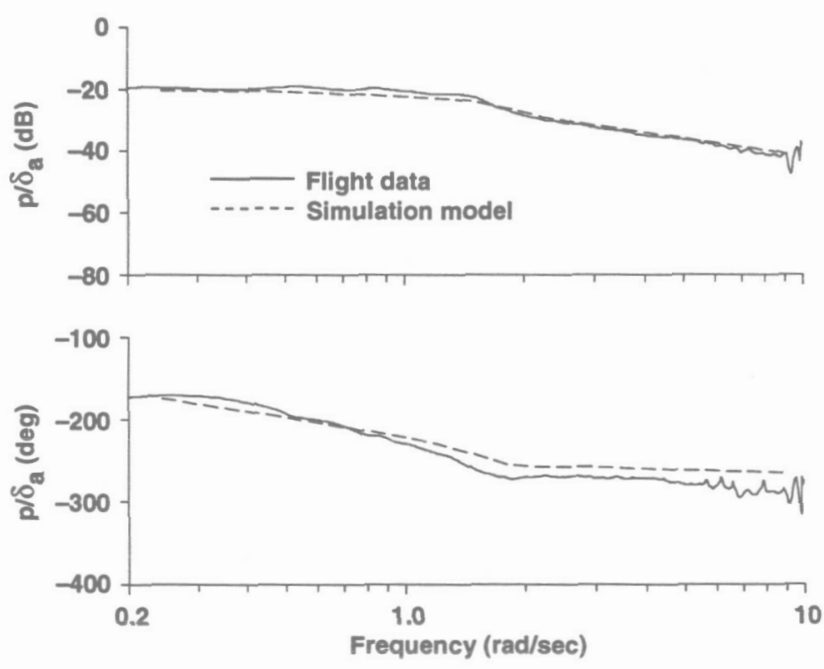

Figure 14. XV-15 tilt-rotor simulation model validation for 170 kts.

factors for significantly improving the model fidelity. For example, 

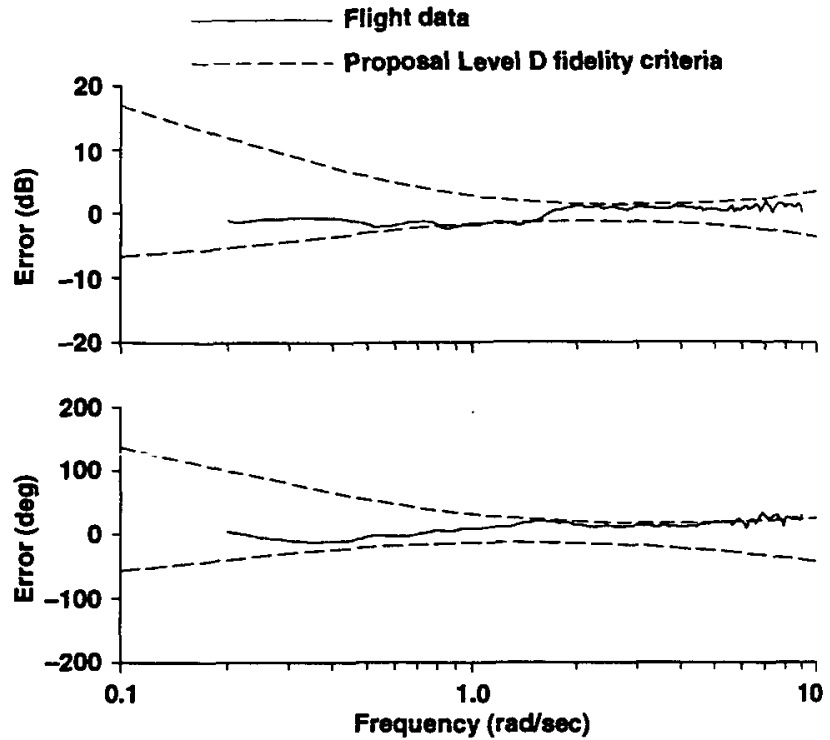

Figure 15. Tilt-rotor math model error functions and proposed fidelity criteria for Level $D$ simulators.

$$
\begin{aligned}
\mathrm{L}_{\text {corrected }}= & \mathrm{f}(\text { nonlin.sim. eqns }) \\
& +\left[\left(\mathrm{L}_{\mathrm{p}}\right)_{\text {flight }}-\left(\mathrm{L}_{\mathrm{p}}\right)_{\text {sim }}\right] \mathrm{p} \\
& +\left[\left(\mathrm{L}_{\delta_{\text {lat }}}\right)_{\text {flight }}-\left(\mathrm{L}_{\delta_{\text {lat }}}\right)_{\text {sim }}\right] \delta_{\text {lat }}+\ldots
\end{aligned}
$$

Identification tools provide a systematic and accurate approach to determine these correction factors which are routinely used by the simulator industry to improve dynamic fidelity.

Comprehensive simulation studies are often used to define flight-control system hardware requirements such as actuator and sensor filter bandwidths. Franklin et al. (1991) used CIFER ${ }^{\circledR}$ to determine actuator bandwidth requirements for a conceptual A/STOVL aircraft. The spectral characteristics of the stabilization and command augmentation system (SCAS) commands to the aircraft control surfaces were obtained for ensemble analyses of simulated flight tasks, and are shown in figure 16. The results indicate a SCAS command signal bandwidth (frequency at $-3 \mathrm{~dB}$ amplitude) of about $4 \mathrm{rad} / \mathrm{sec}$ in pitch and roll, with a significantly lower command bandwidth for the thrust (vertical) axis. Actuator hardware response bandwidths should be 5-10 times the respective SCAS command bandwidths to avoid introducing significant phase lag in the control loops (Franklin et al. 1991). Similar analysis techniques were used by Blanken to determine the effect of control-system design on changes in pilot control bandwidth (workload) and handling qualities. This study included an interesting comparison of pilot work

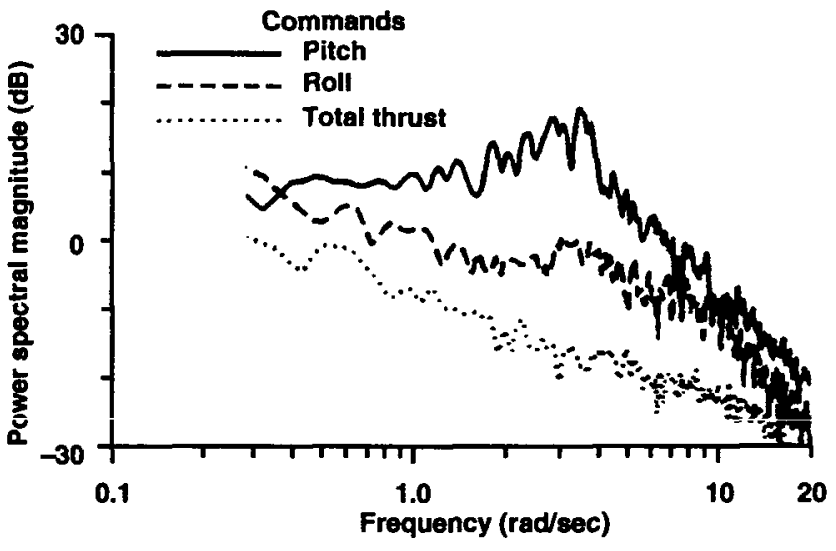

Figure 16. Power spectra of ASTOVL propulsion system commands.

load for the simulation and flight-test environments (Blanken and Pausder 1994).

\section{Development}

At the development stage, flight-control system hardware and software components and subsystems undergo bench testing to verify that the performance characteristics meet the design specifications. Sophisticated flight-control development facilities (DF) or "hot-benches" allow the test of prototype flight software and hardware integrated with the simulated aircraft dynamics. In helicopter development, model or full-scale rotors are dynamically tested in the wind tunnel and the responses are validated against design requirements and comprehensive analysis models. This section presents system-identification techniques to support development stage validation. Examples are drawn from the NASA VSRA project, helicopter actuator tests, and the Sikorsky Bearingless Main Rotor (SBMR) full-scale rotor wind-tunnel tests.

An extensive development facility has been used in the NASA vertical/short takeoff and landing (V/STOL) systems research aircraft (VSRA) project, which equipped a YAV-8B Harrier aircraft with a fly-by-wire research flight-control system (Foster et al. 1987) (fig. 17). The overall flight-control goals of the VSRA program are to assess critical technology elements for advanced short takeoff/vertical landing (STOVL) aircraft, including: integrated flight/propulsion control, advanced control and display laws, and reaction-controlled bleed-flow requirements. The role of the DF has been for verification of control-law flight software, system software, and safety monitoring. Actual flight computers and flight hardware 


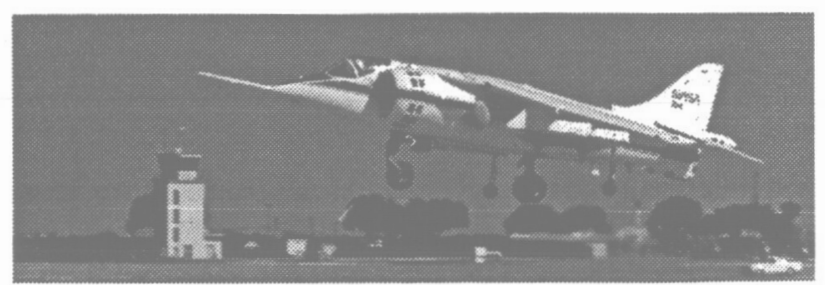

Figure 17. NASA V/STOL system research aircraft (VSRA).

were included in the DF to validate flight systems during the final development stage. The aircraft dynamics are simulated by the VSRA math model, with inputs from a test console or a rudimentary pilot-cockpit station. CIFER ${ }^{\circledR}$ was exercised extensively to validate brokenloop and end-to-end closed-loop frequency responses of the DF flight systems against the design models and theoretical analyses. Signal processing and conditioning algorithms and digital timing were also verified during DF testing.

Actuator system dynamics comprise an important component of the overall high-frequency phase lag in modern flight-control systems. Therefore, flight-control system stability margins and overall closed-loop performance and handling qualities can be significantly degraded if the actuator dynamics do not meet the design specifications. System-identification bench testing of aircraft actuators ensures that expected performance is achieved and that costly modifications can be avoided at the flight-test stage. Frequency-response identification and transferfunction modeling from a typical helicopter actuator test are shown in figure 18. Excellent coherence is achieved over a broad frequency range $(0.2-40 \mathrm{rad} / \mathrm{sec})$ using a computer-generated frequency-sweep excitation. The actuator dynamics are well characterized by the damped second-order response obtained by CIFER ${ }^{\circledR}$ (fig. 18). These component system results are used to update simulation math models and to optimize flight-control system gains prior to first flight.

Structural analysis programs such as NASA structural analysis (NASTRAN) are rarely able to accurately predict the flexible response beyond the first elastic modes of a new aircraft. Therefore, structurally-scaled models or fullscale structural test vehicles are evaluated in special rigs to verify the elastic characteristics and make final adjustments to the structural compensation (e.g., notch filters) in the control system prior to first flight. Automated test/analysis facilities excite the individual structural modes of the aircraft with shakers and then use systemidentification methods to determine model characteristics. For modern rotorcraft development, system identification
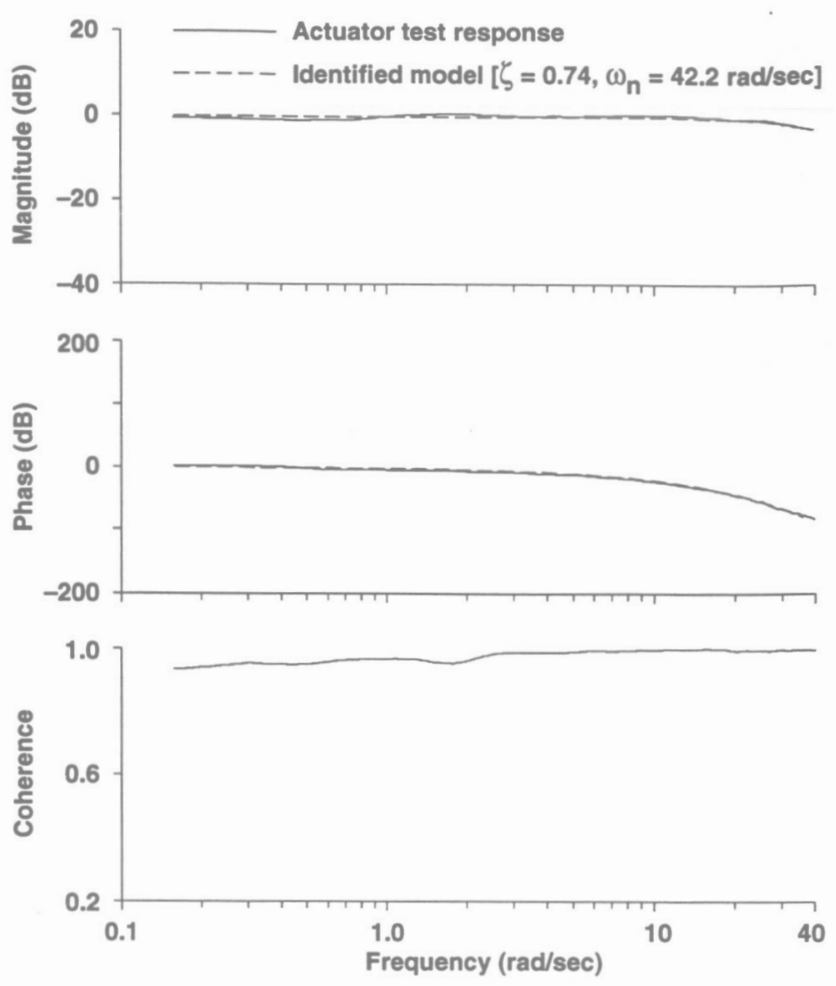

Figure 18. Helicopter actuator response identification and modeling.

has also been effective in extracting dynamic response model of subscaled or full-scale rotor systems from dynamic wind-tunnel test data. The control response dynamics of the SBMR were determined in a joint NASA/Sikorsky test in the Ames 40 - by 80 -Foot Subsonic Wind Tunnel (fig. 19) (Tischler et al. 1994). Computergenerated frequency-sweep excitation signals to the SBMR swashplate actuator were carefully designed to ensure adequate identification within the limitations of the rotor and wind-tunnel stand. Rotor blade and hub moment frequency responses were then extracted using CIFER ${ }^{\circledR}$ and were compared to comprehensive simulation models of the SBMR. CIFER ${ }^{\circledR}$ was also used to extract the rotor's physical parameters based on a linearized $14 \mathrm{DOF}$ analytical formulation of the SBMR dynamics (Tischler et al. 1994).

Figure 20 shows the identified on-axis roll moment response to a lateral stick input. The simulation math model and 14 DOF identified model agree closely with measured responses. The off-axis pitching moment to lateral stick input is shown in figure 21 . Here, the simulation model phase response deviates significantly from both the measured response and identified parametric model, indicating a poor prediction of rotor crosscoupling. 


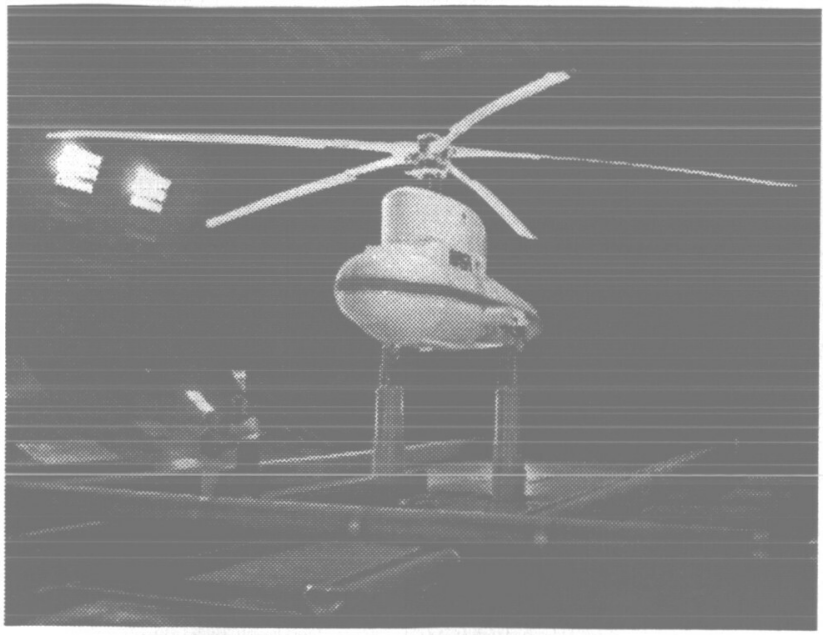

Figure 19. Sikorsky Bearingless Main Rotor (SBMR) test in NASA Ames 40- by 80-Foot Subsonic Wind Tunnel.
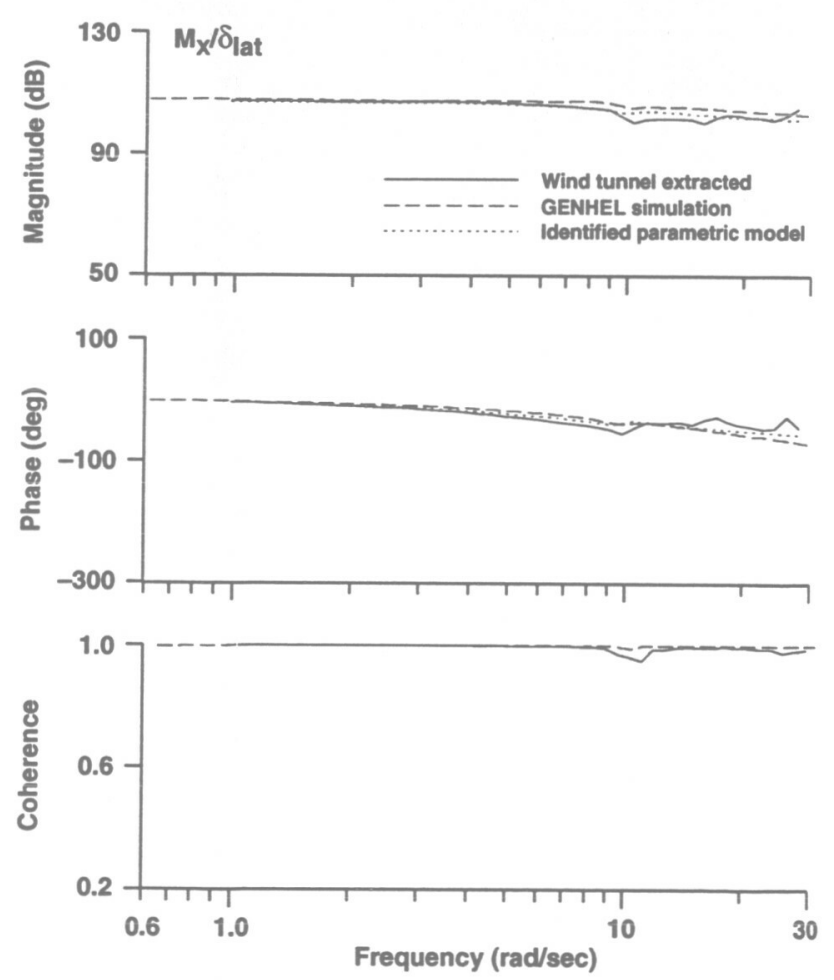

Figure 20. SBMR roll-moment response to lateral-stick input (40-kts flight condition).

The key identified physical parameters of the rotor system are compared with the GenHel simulation values in table 3 (both are updated from the earlier results of Tischler et al. 1994). Many of the important rotor parameters such as Lock number, blade inertia, and effective hinge off-set compare very favorably, and reflect the good on-axis response prediction of the simulation model. The
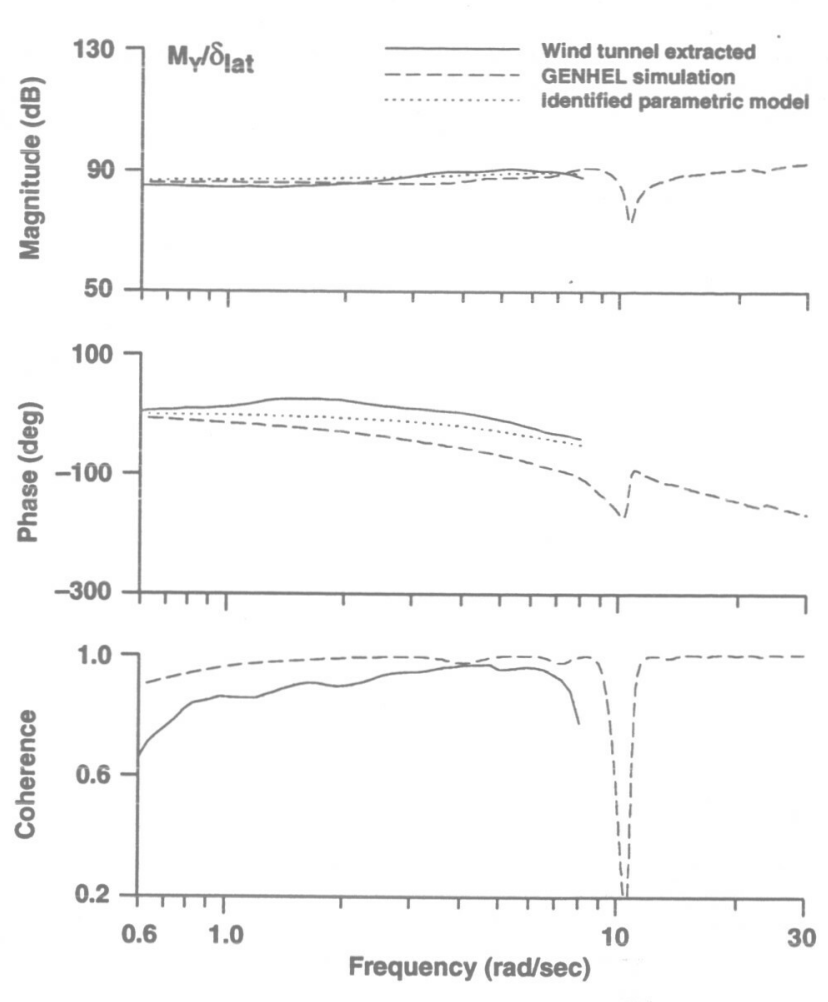

Figure 21. SBMR pitching-moment response to lateralcyclic-stick input (40 kts).

Table 3. Comparison of SBMR identified parameters with GENHEL values

\begin{tabular}{|c|c|c|c|c|}
\hline Rotor Parameter & Symbol & Units & $\begin{array}{r}\text { GENHEL } \\
\text { value }\end{array}$ & $\begin{array}{l}\text { Identified } \\
\text { value }\end{array}$ \\
\hline Lock number ${ }^{1}$ & $\gamma$ & ND & 7.46 & 7.82 \\
\hline Lift-curve slope & a & $1 / \mathrm{rad}$ & 5.73 & 5.33 \\
\hline Blade inertia $^{1}$ & $I_{b}$ & slug- $\mathrm{ft}^{2}$ & 552.81 & 489.8 \\
\hline Blade 1st mass moment ${ }^{1}$ & $s_{b}$ & slug-ft & 38.76 & 48.78 \\
\hline Blade weight & $m_{b} g$ & lbs & 115 & 142.68 \\
\hline Flapping frequency & $v_{\beta}$ & per rev & 1.081 & 1.080 \\
\hline Effective hinge-offset & e & ND & 0.097 & 0.095 \\
\hline Lag frequency & vל & per rev & 0.699 & 0.697 \\
\hline Lag damper & $c_{\zeta}^{3}$ & $\mathrm{ft}-\mathrm{lb}-\mathrm{sec} / \mathrm{rad}$ & 372 & 473.29 \\
\hline Collective-lag/shaft freq. & $v \zeta_{0}$ & per rev & - & 0.474 \\
\hline Collective-lag/shaft damping & $c_{\xi_{0}}$ & $\mathrm{ft}-\mathrm{lb}-\mathrm{sec} / \mathrm{rad}$ & - & 1631.49 \\
\hline Trim coning angle & $\beta_{\mathrm{T}}^{\infty}$ & $\mathrm{rad}$ & 0.0768 & 0.0654 \\
\hline Pitch-flap coupling & $\mathbf{K}_{\mathbf{P}_{\beta}}$ & $\mathrm{rad} / \mathrm{rad}$ & 0 & 0 \\
\hline Pitch-lag coupling & $K_{\mathbf{p} \zeta}^{p}$ & $\mathrm{rad} / \mathrm{rad}$ & -0.0225 & -0.184 \\
\hline Control phase angle & $\Delta \mathrm{SP}$ & $\operatorname{deg}$ & -14.0 & -23.4 \\
\hline
\end{tabular}

IMPORTANT NOTE:

1 Mass moment parameters and Lock number are referenced to the hub center and not to the hinge-axis.

important difference between the identified model and the GenHel simulation is the control-phase angle. This parameter has a known geometric value of -14 deg in the wind-tunnel tests, but the identified value needed to capture the measured off-axis response of figure 21 is $-23.4 \mathrm{deg}$. This discrepancy in control phasing indicates a fundamental problem in the aerodynamic modeling of the 
rotor. Follow-on analysis of these results have yielded a new approach for correcting the simulation math model and improvements in the identification methods for freeflight results (Takahashi et al. 1995). Accurate crosscoupling prediction is especially important for the design of decoupling compensators in modern rotorcraft flightcontrol systems. Corrections to the flight-control laws prior to final flight software installation and vehicle testing reduces development flight-test costs and improves the final performance of the system.

\section{Flight Testing}

The flight-test program for flight-control and handlingqualities validation and optimization has a significant impact on the overall development schedule and cost for modern fly-by-wire aircraft. System identification provides a critical technology for tracking aircraft dynamic response performance into flight, solving problems that arise in flight tests, and rapidly optimizing control system parameters. This section presents system-identification methods for control system flight testing. Flight data results are presented for the VSRA and UH-60A Rotorcraft Aircraft Systems Concept Airborne Laboratory (RASCAL) projects.

Flight test verification of aero-servo-elastic stability margins is an important concern for modern fly-by-wire aircraft, where dynamic coupling of the high-gain flight control system with light-weight structural dynamics can degrade flutter stability. Flutter margin verification using system identification has been adopted by British Aerospace in the development of a series of fly-by-wire high-performance aircraft, as described by Caldwell (1994). Near real-time system identification was employed during the X-29 aircraft flight testing (Clarke et al. 1994) for on-line verification of stability margins in a highly-efficient flight envelope expansion program. Piloted frequency sweeps were used to excite the vehicle structural modes at each test condition, and the telemetered data were then analyzed using high-speed array processing computers. Once the stability margins were verified, the pilot was cleared to proceed to the next flight condition, avoiding the normally time-consuming test technique of clearing one flutter test point per flight. In a similar application of near real-time identification technqiues, CIFER ${ }^{\circledR}$ was used to support flight tests of the "Pathfinder," a large high-altitude solar Unmanned Air Vehicle (UAV) (Dornheim 1995). Servoloop stability margins were extracted based on telemetered data from computer-generated frequency-sweep tests, and then compared with simulation predictions. When the CIFER ${ }^{\circledR}$ results indicated a loss of stability margins at a high altitude flight condition, the ground station pilot executed real-time switching commands to adjust the Pathfinder control law gains.

Theoretical analyses of the XV-15 tilt-rotor aircraft (fig. 13) predicted that the reduction of whirl mode flutter stability margins with increasing flight speed would limit the aircraft's usable flight envelope. An extensive flighttest program was conducted to verify the expected margins. Early testing using the traditional dwell-delay method proved time-consuming and resulted in considerable data scatter. Acree and Tischler (1993) conducted automated frequency-sweep tests using wing flaperon excitation and subsequently analyzed the data using the CIFER $^{\circledR}$ identification tools. The frequency-domain test technique proved to be much more time-efficient, and the results showed both a reduction in the scatter at specific conditions and an improvement in consistency across flight conditions.

Automated frequency-sweep flight testing was also conducted on the VSRA YAV-8B aircraft (Foster et al. 1987) (fig. 17) to determine the locations of the (open-loop) first and second structural wing-bending modes, and to verify actuator and sensor processing dynamics. The parametric model shown in figure 22 was obtained from CIFER ${ }^{\circledR}$, and includes the rigid-body response and second-order representations of the two structural modes. Notch filters, included to avoid coupling of the flight-control and aeroelastic dynamics, and control-law gains were subsequently updated based on these identification results. Piloted frequency-sweep flight testing was also conducted in the VSRA program to document the final stability margins and closed-loop response for a number of flight conditions. The broken-loop pitch response for 120 knots as obtained from CIFER ${ }^{\circledR}$ is shown in figure 23 . The figure shows that the dynamics are conditionally stable, with a minimum crossover frequency of $1 \mathrm{rad} / \mathrm{sec}$ required for closed-loop vehicle stability. The nominal crossover frequency of $4 \mathrm{rad} / \mathrm{sec}$ yields a phase margin of $40 \mathrm{deg}$ (acceptable). A gain margin of about $8 \mathrm{~dB}$ is indicated over the broad frequency range $15-30 \mathrm{rad} / \mathrm{sec}$ were the phase curve has a nearly constant value of about -180 deg.

The identified closed-loop response dynamics are shown in figure 24. In the frequency range of $0.3-5 \mathrm{rad} / \mathrm{sec}$ the response is accurately modeled by a well-damped secondorder system:

$$
\frac{\theta}{\theta_{\mathrm{com}}}=\frac{6.35 \mathrm{e}^{-0.048 \mathrm{~s}}}{[0.953,2.47]}
$$


YAV-8B Aeroelastic Identification (120 Kts)
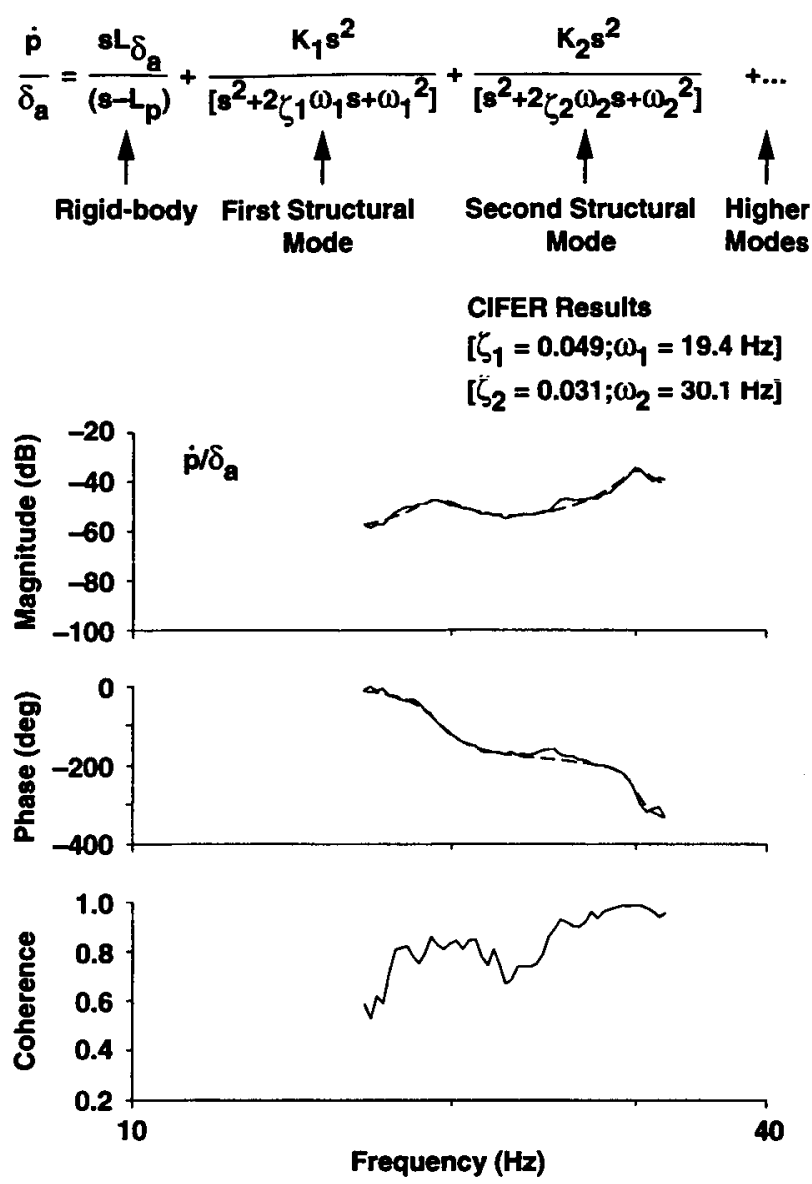

Figure 22. YAV-8B aero-elastic wing-bending identification (120 kts).

These dynamics closely match the design response of:

$$
\frac{\theta}{\theta_{\text {com }}}=\frac{4.0}{[1.0,2.0]}
$$

The small equivalent time delay of $\tau=48 \mathrm{msec}$ reflects the VSRA high-bandwidth fly-by-wire actuators and rapid digital calculations, and suggests no time-delay related handling-qualities problems.

In some applications, simulation math models are not sufficiently accurate for control-law design prior to first flight. For example, the current state-of-the-art of rotorcraft flight dynamics simulation yields a fair prediction of the on-axis characteristics, but usually an inadequate prediction of the cross-coupling response as in the baseline simulation result of figure 21 , often not even correct in sign (Curtiss 1992). Rotorcraft math models are still useful for initial simulation and control-law development efforts, but are less satisfactory for the final determination

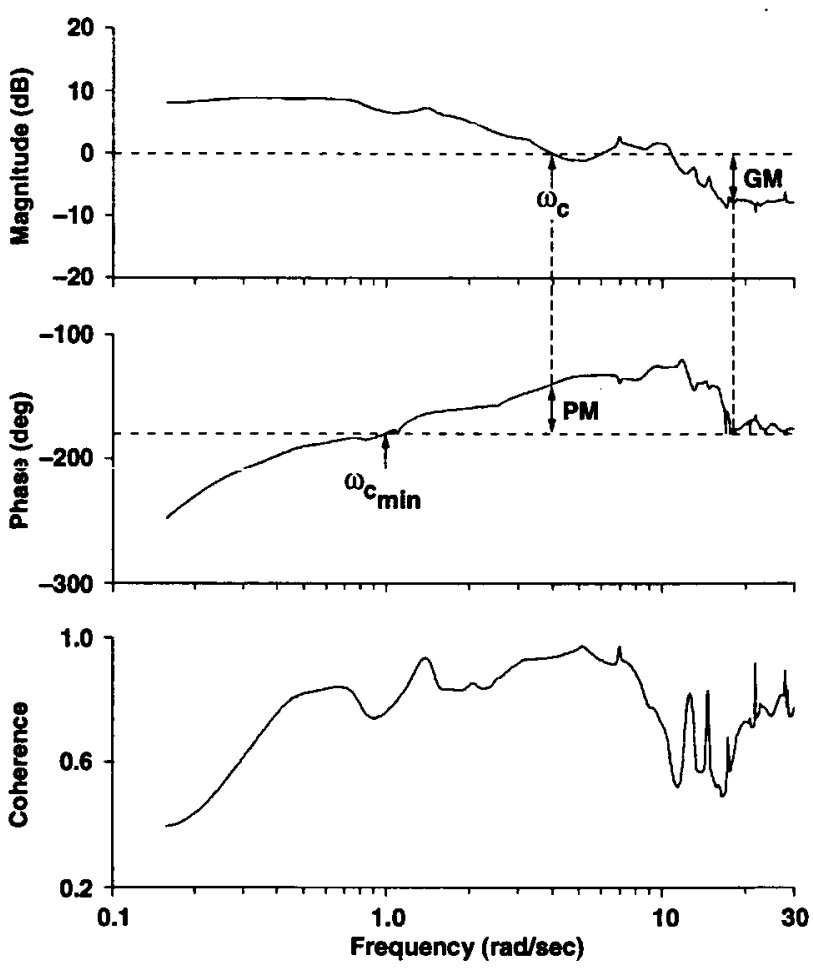

Figure 23. VSRA broken-loop pitch response (120 kts).
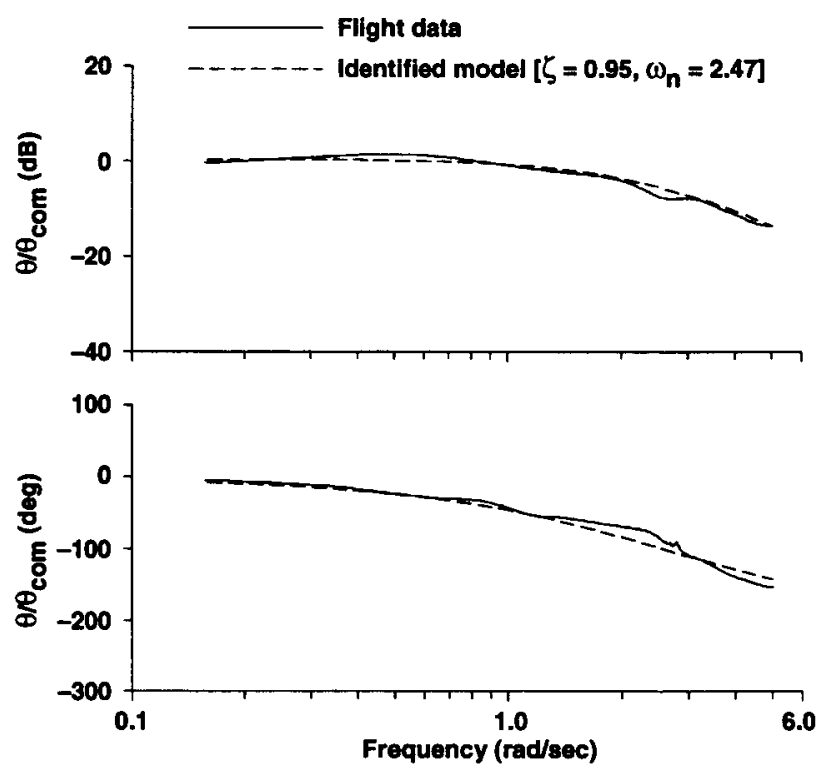

Figure 24. VSRA closed-loop pitch response (120 kts).

of stability margins and decoupling controller gains. Initial flight tests with the SCAS-OFF or with reduced control system gains can be conducted to identify new aircraft dynamics or to update the simulation for final control-law parameter selection. The DLR developed a high-bandwidth flight-control system for the Bo-105 
variable-stability aircraft (ATTHeS) based directly on bare-airframe state-space models extracted from flight data using frequency-domain system identification (von Grunhagen et al. 1994). This direct use of flight-identified state-space models for control-law design represents the most sophisticated and demanding application of systemidentification tools.

An approach similar to that of the DLR has been adopted by the AFDD/NASA in the development of an advanced fly-by-wire flight-control system for the RASCAL UH-60A helicopter (Takahashi et al. 1995), which uses the same airframe as the ADOCS demonstrator (fig. 3). Extensive theoretical studies of combat rotorcraft controllaw concepts for application to RASCAL have been conducted by Takahaski (1994) and Cheng et al. (1995) based on UH-60A simulation math models. At the same time, Fletcher (1995) has conducted UH-60A flight tests and comprehensive frequency-domain identification studies to extract high-order state-space models of the aircraft for hover and cruise flight conditions. These efforts were brought together in the RASCAL control-law study described in Takahashi et al. (1995). Figures 25 and 26 compare two flight-mechanics-simulation math models (" $A$ " and " $B$ ") used for the control-law designs with the bare-airframe flight-test data. The on-axis roll response agreement between the math models and the flight-test data is reasonable at mid-frequency $(0.8-10 \mathrm{rad} / \mathrm{sec})$, but is inadequate beyond $10 \mathrm{rad} / \mathrm{sec}$ due to errors in the prediction of the in-plane rotor response. Large errors are also seen at low frequency. The simulation models show poor predictive capability for the cross-coupling response of roll rate to longitudinal stick input, with large phase errors in the critical frequency range of $1-10 \mathrm{rad} / \mathrm{sec}$ (fig. 26). While the simulation models were sufficient for the preliminary flight-control and simulation studies, they are clearly inadequate for selecting final flight gainsespecially for the response decoupling parameters.

The identified higher-order linear model is compared with the flight data and the simulation models in Figures 25 and 26. Significant improvement in the on-axis prediction is seen for both the high-frequency (rotor response) and lower-frequency dynamics. The identified model also tracks the off-axis magnitude and phase very closely, showing clear improvement compared to the two simulation models. The excellent predictive capability of the identified model is also seen in the time response comparison of figure 27.

The identified state-space model was then substituted into the model-following control system block diagram in place of the original simulation model ("A") response to check the expected flight characteristics. Figure 28 shows The identified state-space model was then substituted into
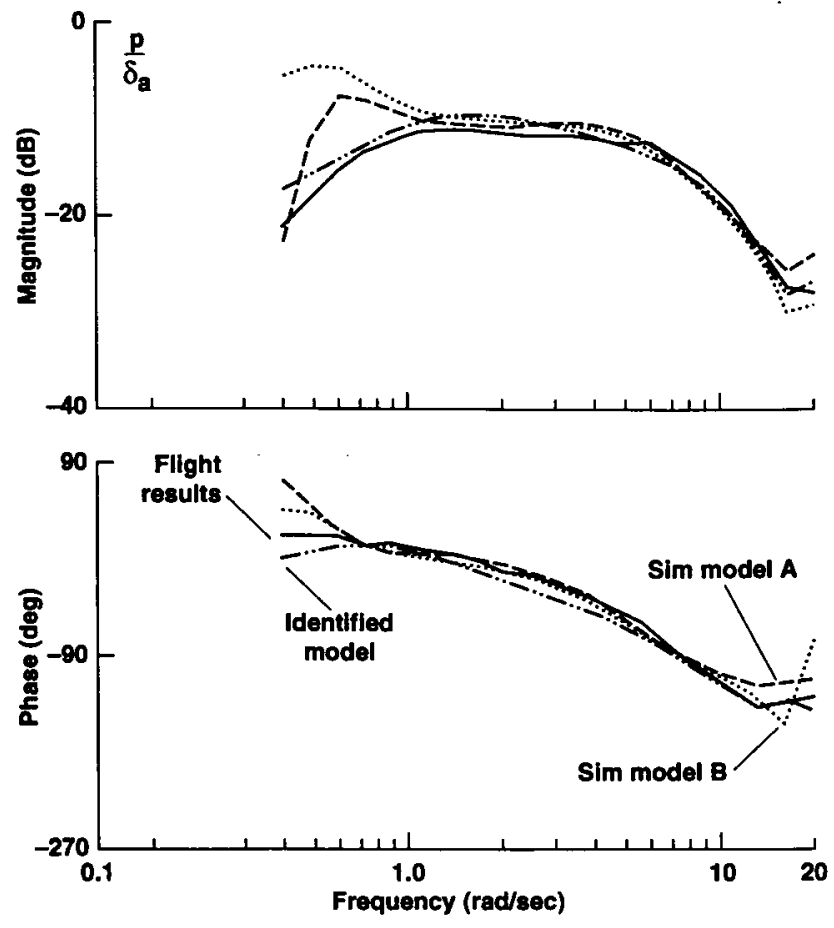

Figure 25. UH-60A on-axis roll-rate response to lateral stick (hover); comparison of simulation and identified statespace model with flight data.
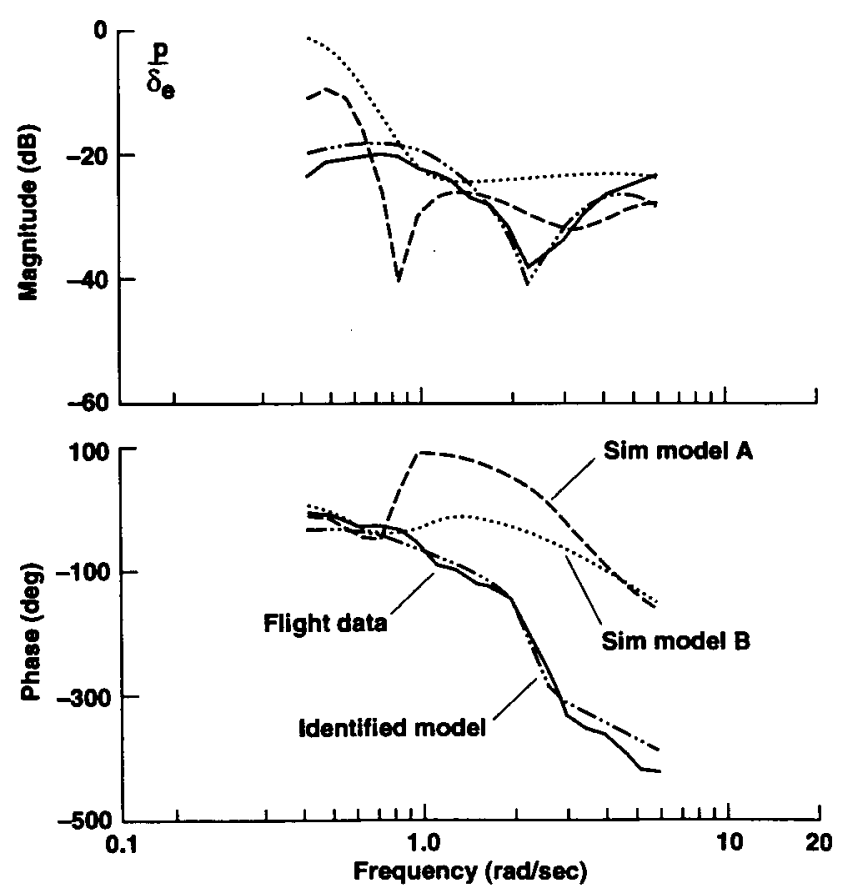

Figure 26. UH-60A off-axis roll-rate response to longitudinal stick (hover); comparison of simulation and identified state-space model with flight data. 

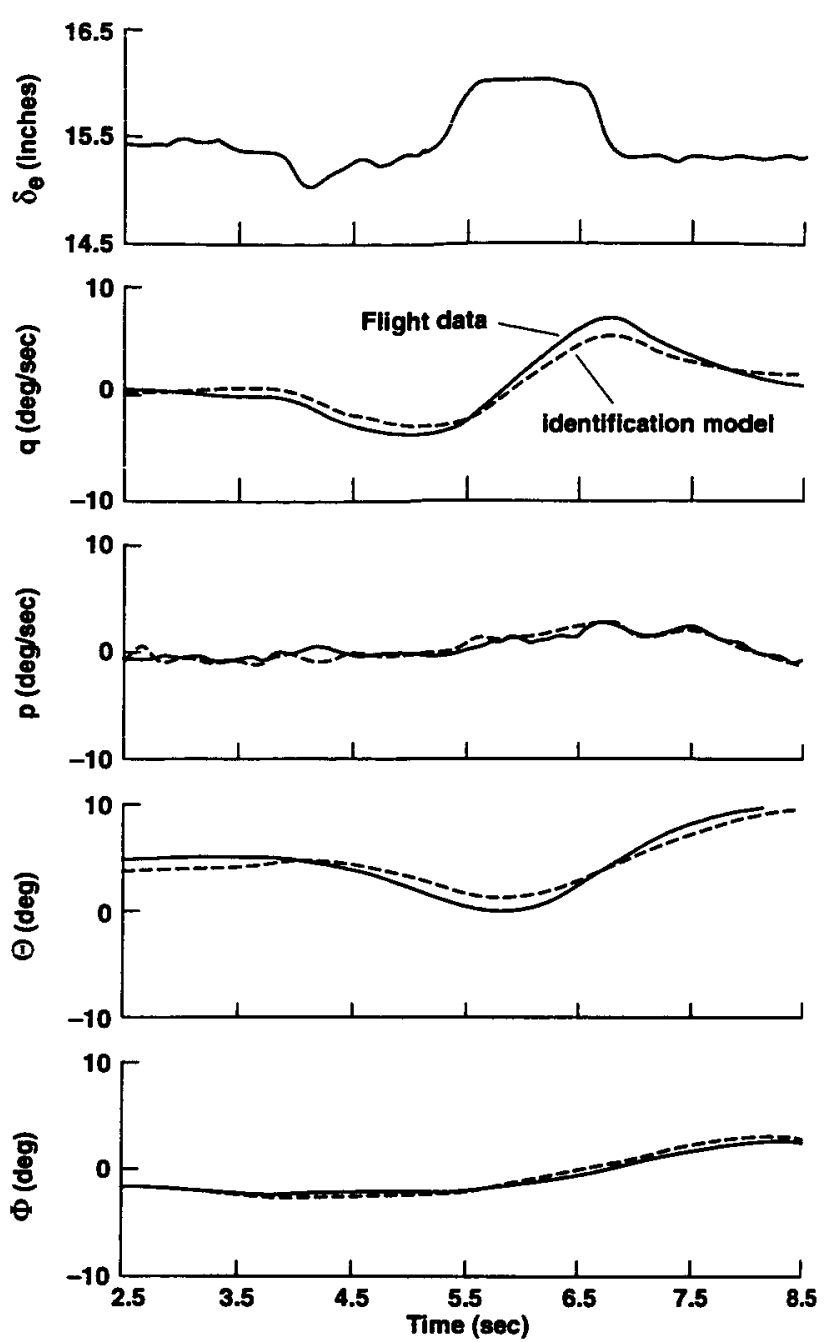

Figure 27. Time response comparison of UH-60A identification model and flight data.
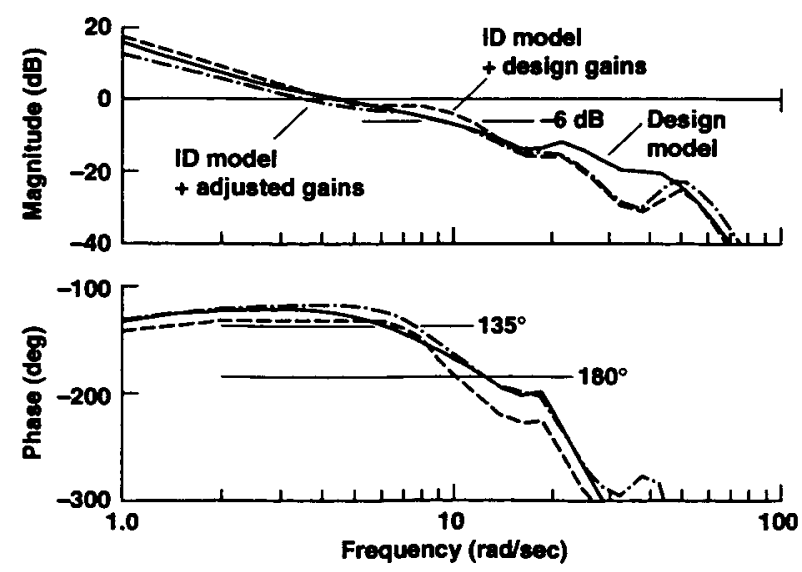

Figure 28. RASCAL UH-60A broken-loop roll response in hover. the model-following control system block diagram in place of the original simulation model ("A") response to check the expected flight characteristics. Figure 28 shows that the design phase margin is significantly degraded when the identified model is incorporated. Further, the level of closed-loop cross-coupling (fig. 29) increases by $20 \mathrm{~dB}$ ( $\mathrm{a}$ factor of 10) in the critical handling-qualities frequency range of 1-10 rad/sec. The control-system design parameters were then retuned for the identified model response. Figure 28 shows that the original design crossover frequency, phase margin, and gain margin are recovered. Also, the cross-coupling level for the retuned system closely tracks the coupling levels for the original control-system design (fig. 29).

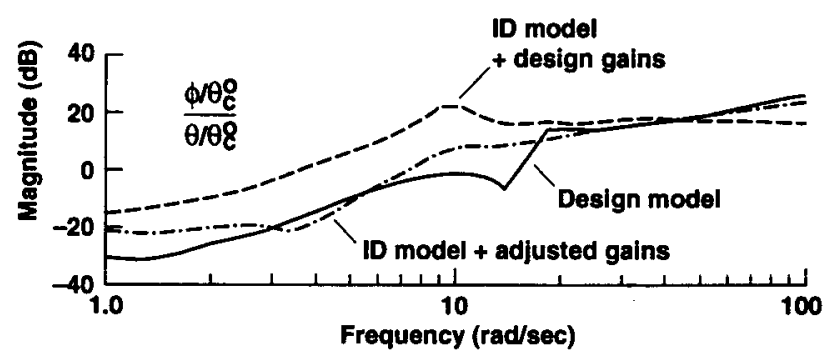

Figure 29. RASCAL UH-60A coupling response of roll-rate due to longitudinal input for hover.

The full exploitation of system-identification tools early in the flight-test development and control system optimization effort has been illustrated for the Bo-105 (ATTHeS) and UH-60A (RASCAL) programs. This approach will significantly reduce flight-test development time for new aircraft, and will expedite the optimization of flight-control system performance and handling qualities.

\section{Concluding Remarks}

1. System identification is a full life-cycle technology that supports aircraft flight-control system development from design specification through flight-test optimization. Significant reductions in development time and costs are realized by tracking open and closed-loop dynamic response characteristics through the development process.

2. Frequency-domain system-identification methods are well suited to aircraft flight-control development since many current design specifications, design and analysis techniques, and acceptance flight-test techniques are based in the frequency domain. 
3. Reliable computational tools for system identification are available and have been successfully employed in many recent aircraft programs.

4. System identification is especially effective in providing a transparent and integrated understanding of handling-qualities characteristics and system stability. Considerable improvements in system performance are facilitated by the rapid availability of accurate end-to-end and subsystem dynamic models.

\section{References}

Acree, C. W., Jr.; and Tischler, M. B.: Determining XV-15 Aeroelastic Modes from Flight Data with Frequency-Domain Methods. NASA Technical Paper 3330, ATCOM Technical Report 93-A004, 1993.

Anon.: Military Specification, Flying Qualities of Piloted Airplanes, MIL-F-8785 (ASG), 1954.

Anon: Helicopter Flying and Ground Handling Qualities; General Requirements for MIL-H-8501A, 1961.

Anon.: Military Specification, Flight Control SystemsGeneral Specification for Design, Installation, and Test of Piloted Aircraft, MIL-F-9490D (USAF), 1975.

Anon.: Military Standard, Flying Qualities of Piloted Vehicles, MIL-STD-1797 (USAF), 1987.

Anon.: Aeronautical Design Standard, Handling Qualities Requirements for Military Rotorcraft, ADS-33C (AVSCOM), 1989.

Anon.: Rotorcraft System Identification AGARD AR 280, 1991.

Atencio, A.: Fidelity Assessment of a UH-60A Simulation on the NASA Ames Vertical Motion Simulator. NASA TM-104016, 1993.

Ballin, M. G.; and Dalang-Secretan, M. A.: Validation of the Dynamic Response of a Blade-Element UH-60A Simulation Model in Hovering Flight. J. Amer. Hel. Soc., vol. 36, no. 4, 1991, pp. 77-88.

Blanken C. L.; and Pausder, H. -J.: Investigation of the Effects of Bandwidth and Time Delay on Helicopter Roll-Axis Handling Qualities. J. Amer. Hel. Soc., vol. 39, no. 3, 1994, pp. 24-33.
Buchholz, J. J.; Bauschat, J. M.; Hahn, K. U.; and Pausder, H. J.: ATTAS \& ATTHeS In-Flight Simulators: Recent Application Experiences and Future Programs, AGARD Flight Vehicle Integration Panel Symposium "Simulation: Where are the Challenges," Braunschweig, Germany, 1995.

Caldwell, B. D.: The FCS-Structural Coupling Problem and its Solution. AGARD-CP-560, Paper 16, 1994.

Cheng, R. P.; Tischler, M. B.; and Biezad, D. J.: Rotorcraft Flight Control Design Using Quantitative Feedback Theory, Symposium on Quantitative Feedback Theory, 2-4 August, Purdue University, West Lafayette, Ind., 1995.

Churchill, G. B.; and Dugan, D. C.: Simulation of the XV-15 Tilt Rotor Research Aircraft. NASA TM-84222, 1982.

Clarke, R.; Burken, J. J.; Bosworth, J. T.; and Bauer, J. E.: X-29 Flight Control System: Lessons Learned. International J. Contr., vol. 59, no. 1, 1994, pp. 199-219.

Curtiss, H. C., Jr.: On the Calculation of the Response of Helicopter to Control Inputs. 18th European Rotorcraft Forum, Avignon, France, 1992.

Dornheim, Michael A.: Aviation Week and Space Tech., Sept. 18, 1995, p. 67.

Engelland, S. A.; Franklin, J. A.; and McNeill, W. E.: Simulation Model of a Mixed-Flow Remote-Lift STOVL Aircraft. NASA TM-102262, 1990.

Fletcher, J. W.: Identification of UH-60A Stability Derivative Models in Hover from Flight Test Data. J. Amer. Hel. Soc., vol. 40, no. 1, 1995.

Foster, J. D.; Moralez, E, III; Franklin, J. A.; and Schroeder, J. A.: Integrated Control and Display Research for Transition and Vertical Flight on the NASA V/STOL Research Aircraft (VSRA). NASA TM-100029, 1987.

Franklin, J. A.; Stortz, M. W.; Engelland, S. A.; Hardy, G. H.; and Martin, J. L.: Moving Base Simulation Evaluation of Control System Concepts and Design Criteria for STOVL Aircraft. NASA TM-103843, 1991.

Glusman, S. I.; Dabundo, C.; and Landis, K. H.: Evaluation of ADOCS Demonstrator Handling Qualities. Proceedings of the 43rd Annual National Forum of the American Helicopter Society, Washington, D.C., 1987. 
Hamel, P. G.; and Jategaonkar, R. V.: The Evolution of Flight Vehicle System Identification. AGARD Structures and Materials Panel Specialists' Meeting on Advanced Aeroservoelastic Testing and Data Analysis, Rotterdam, The Netherlands, 1995.

Hoh, R. H.; and Ashkenas, I. L.: Development of VTOL Flying Qualities Criteria for Low Speed and Hover. Systems Technology, Inc., Hawthorne, Calif., TR-1116-1, 1979.

Hoh, R. H.; Mitchell, D. G.; Ashkenas, I. L.; Klein, R. H.; Heffley, R. K.; and Hodgkinson, J.: Proposed MIL Standard and Handbook-Flying Qualities of Air Vehicles. AFWAL-TR-82-3081, vol. 2, 1982.

Hoh, R. H.; Mitchell, D. G.; Aponso, B. L.; Key, D. L.; and Blanken, C. L.: Proposed Specification for Handling Qualities of Military Rotorcraft. Vol. 1Requirements. U.S. Army Aviation Systems Command, TR 87-A-4, 1988.

Kaletka, J.; and Fu, K. -H.: Frequency-Domain Identification of Unstable Systems Using X-31 Aircraft Flight Test Data. AIAA-93-3635, AIAA Atmospheric Flight Mechanics Conference, Monterey, Calif., 1993.

Kaletka, J.; and von Grunhagen, W.: Identification of Mathematical Derivative Models for the Design of a Model Following Control System. 45th Annual Forum of the American Helicopter Society, Boston, Mass., 1989.

MATLAB ${ }^{\circledR}:$ High-Performance Numeric Computation and Visualization Software. The Math Works, Inc., Reference Guide, 1992.

McFarland, R. E.: Transport Delay Compensation for Computer-Generated Imagery Systems. NASA TM-100084, 1988.

Moorhouse, D. J.; and Citurs, K. D.: The Control System Design Methodology of the STOL and Maneuver Technology Demonstrator. International J. Contr., vol. 59, no. 1, 1994, pp. 221-238.
Takahashi, M. D.: Rotor-State Feedback in the Design of Flight Control Laws for a Hovering Helicopter. J. Amer. Hel. Soc., vol. 39, no. 1, 1994, pp. 50-62.

Takahashi, M. D.; Fletcher, J. W.; and Tischler, M. B.: Development of a Model Following Control Law for Inflight Simulation Using Analytical and Identified Models. American Helicopter Society, 51th Annual Forum, Fort Worth, Tex., 1995.

Tischler, M. B.: Frequency-Response Identification of XV-15 Tilt-Rotor Aircraft Dynamics. NASA TM-89428, 1987.

Tischler, M. B.: System Identification Requirements for High-Bandwidth Rotorcraft Flight Control System Design. J. Guid., Contr., and Dyn., vol. 13, no. 5, 1990, pp. 835-841.

Tischler, M. B.; and Cauffman, M. G.: FrequencyResponse Method for Rotorcraft System Identification: Flight Applications to BO 105 Coupled Rotor/Fuselage Dynamics. J. Amer. Hel. Soc., vol. 37, no. 3, 1992, pp. 3-17.

Tischler, M. B.; Driscoll, J. T.; Cauffman, M. G.; and Freedman, C. J.: Study of Bearingless Main Rotor Dynamics from Frequency-Response Wind Tunnel Test Data. American Helicopter Society Aeromechanics Specialists Conference, San Francisco, Calif., 1994.

Tischler, M. B.; Fletcher, J. W.; Morris, P. M.; and Tucker, G. E.: Flying Quality Analysis and Flight Evaluation of a Highly Augmented Combat Rotorcraft. J. Guid., Contr., and Dyn., vol. 14, no. 5, 1991, pp. 954-963.

von Grunhagen, W.; Bouwer, G.; Pausder, H. -J., Henschel, F.; and Kaletka, J.: A High Bandwidth Control System for a Helicopter In-Flight Simulator. International J. Contr., vol. 59, no. 1, 1994, pp. 239-261. 
\begin{tabular}{|l|l|l|} 
1. AGENCY USE ONLY (Leave blank) & 2. REPORT DATE & 3. REPORT TYPE AND DATES COVERED
\end{tabular}

October 1995

Technical Memorandum

4. TITLE AND SUBTITLE

System Identification Methods for Aircraft Flight Control

Development and Validation

6. AUTHOR(S)

$505-59-36$

Mark B. Tischler

7. PERFoRMING ORganization NAME(S) AND ADDRESS(ES)

Aeroflightdynamics Directorate, U.S. Army ATCOM, Ames Research Center, Moffett Field, CA 94035-1000

5. FUNDING NUMBERS

Ames Research Center, Moffett Field, CA 94035-1000

9. SPONSORING/MONITORING AGENCY NAME(S) AND ADDRESS(ES)

National Aeronautics and Space Administration

Washington, DC 20546-0001 and U.S. Army Aviation and Troop

Command, St. Louis, MO 63120-1798

8. PERFORMING ORGANIZATION

REPORT NUMBER

A-950097

10. SPONSORING/MONITORING AGENCY REPORT NUMBER

NASA TM-110369

USAATCOM TR-95-A-007

11. SUPPLEMENTARY NOTES

Point of Contact: Mark B. Tischler, Ames Research Center, MS 211-2, Moffett Field, CA 94035-1000; (415) 604-5563

12a. DISTRIBUTION/AVAILABILITY STATEMENT

12b. DISTRIBUTION CODE

Unclassified-Unlimited

Subject Category - 08

\section{ABSTRACT (Maximum 200 words)}

System-identification methods compose a mathematical model, or series of models, from measurements of inputs and outputs of dynamic systems. The extracted models allow the characterization of the response of the overall aircraft or component subsystem behavior, such as actuators and on-board signal processing algorithms. This paper discusses the use of frequency-domain system-identification methods for the development and integration of aircraft flight-control systems. The extraction and analysis of models of varying complexity from nonparametric frequency-responses to transfer-functions and high-order state-space representations is illustrated using the Comprehensive Identification from $\underline{\text { FrEquency }} \underline{\text { Responses }}\left(\mathrm{CIFER}^{\circledR}\right.$ ) system-identification facility. Results are presented for test data of numerous flight and simulation programs at the Ames Research Center including rotorcraft, fixed-wing aircraft, advanced short takeoff and vertical landing (ASTOVL), vertical/short takeoff and landing (V/STOL), tiltrotor aircraft, and rotor experiments in the wind tunnel. Excellent system characterization and dynamic response prediction is achieved for this wide class of systems. Examples illustrate the role of system-identification technology in providing an integrated flow of dynamic response data around the entire life-cycle of aircraft development from initial specifications, through simulation and bench testing, and into flight-test optimization.

\begin{tabular}{|c|c|c|c|}
\hline \multirow{2}{*}{\multicolumn{3}{|c|}{$\begin{array}{l}\text { 14. SUBJECT TERMS } \\
\text { System identification, Flight control, Flight test }\end{array}$}} & $\begin{array}{l}\text { 15. NUMBER OF PAGES } \\
22\end{array}$ \\
\hline & & & $\begin{array}{l}\text { 16. PRICE CODE } \\
\text { A03 }\end{array}$ \\
\hline $\begin{array}{l}\text { 17. SECURITY CLASSIFICATION } \\
\text { OF REPORT } \\
\text { Unclassified }\end{array}$ & $\begin{array}{l}\text { 18. SECURITY CLASSIFICATION } \\
\text { OF THIS PAGE } \\
\text { Unclassified }\end{array}$ & $\begin{array}{l}\text { 19. SECURITY CLASSIFICATION } \\
\text { OF ABSTRACT }\end{array}$ & 20. LIMITATION OF ABSTRACT \\
\hline
\end{tabular}

